\title{
Espécies de Parmotrema (Parmeliaceae, Ascomycota) do litoral centro-sul do estado de São Paulo III. Grupos químicos equinocárpico e stíctico
}

\author{
Michel Navarro Benatti ${ }^{1,2}$ e Marcelo Pinto Marcelli ${ }^{1}$
}

Recebido em 14/04/2009. Aceito em 28/06/2009

\begin{abstract}
RESUMO - (Espécies de Parmotrema sensu stricto (Parmeliaceae, Ascomycota) do litoral centro-sul do estado de São Paulo III. Grupos químicos equinocárpico e stíctico). O levantamento das espécies pertencentes aos gêneros de grandes parmélias do litoral centro-sul do Estado de São Paulo revelou a ocorrência de sete espécies de Parmotrema sensu stricto (talos foliosos de lobos arredondados em geral com mais de $0,5 \mathrm{~cm}$ larg. com margens inferiores não rizinadas) contendo como constituintes químicos medulares os ácidos equinocárpico ou stíctico. São tipicamente reconhecidos pela forte cor amarela que resulta dos testes de coloração com hidróxido de potássio. São apresentados chave de identificação, descrições, comentários e ilustrações baseados em material brasileiro.
\end{abstract}

Palavras-chave: costões rochosos, liquens, manguezal, restinga

ABSTRACT - (Species of Parmotrema sensu strict (Parmeliaceae, Ascomycota) from the central-southern coast of São Paulo state II. Chemical groups equinocarpic and stictic). In a survey of the species pertaining to genera of large parmeliae occurring in the coastal areas of the central-southern coast of São Paulo state, Brazil, seven species of Parmotrema sensu stricto (foliose thalli with rounded lobes usually more than 0.5 mm wide with nude lower margins) containing equinocarpic or stictic acids as the main medullar substances were found. These are typically recognized by the strong yellow- staining potassium hydroxide spot test. An identification key, descriptions, comments, and illustrations based on Brazilian material are provided for these species.

Key words: rocky shores, lichens, mangrove, restinga

\section{Introdução}

O gênero Parmotrema A. Massal. é caracterizado pelos lobos de ápices largos e arredondados (com mais de $0,5 \mathrm{~cm}$, muitas vezes ultrapassando 2 ou $3 \mathrm{~cm}$ de largura), ausência de pseudocifelas (poros com extravasamento de hifas medulares), ocorrência freqüente de cílios marginais, ampla zona marginal do córtex inferior nua, rizinas geralmente simples, e ascósporos elipsóides de paredes espessas (Brodo et al. 2001; Nash \& Elix 2002). Mais de trezentas espécies são conhecidas em todo o mundo (Nash \& Elix 2002), das quais aproximadamente um terço é citado para o Brasil (Marcelli 2004).

Todas as espécies apresentadas neste trabalho possuem como característica comum a presença dos ácidos equinocárpico ou stíctico medulares, ambos reconhecidos por apresentarem testes de coloração com reações $\mathrm{K}+$ amarelo forte e $\mathrm{P}+$ alaranjado. Em CCD estas substâncias apresentam $\mathrm{Rfs}$, arrastes e colorações bem diferentes observados após a revelação cromatográfica.

A área abrangida por esta pesquisa e seus respectivos dados climáticos são descritos em Benatti \& Marcelli (2009). Ela está localizada no litoral centro-sul do estado de São Paulo, entre as municipalidades de Bertioga e Cananéia.

Este trabalho objetivou realizar o levantamento das espécies de Parmotrema sensu stricto com ácidos equinocárpico e estíctico medulares que ocorrem nos diversos ambientes do litoral centro-sul paulista, até então inexistente. São fornecidos chave artificial de identificação, descrições comentadas, dados das localidades e de ambientes para as espécies encontradas.

\section{Material e métodos}

Os ambientes estudados incluem (1) os costões rochosos, quase sempre despidos de vegetação e expostos à forte insolação, à salinidade da maré e a ação altamente energética das ondas, (2) a vegetação de restinga, constituída pelas matas de jundu e as florestas de restinga, que compõem grande parte da vegetação da planície costeira atrás da faixa das dunas, instaladas sobre as extensas faixas arenosas na orla marítima, e (3) os manguezais, formações caracterizadas pelas florestas que se erguem sobre um substrato plano, lodoso, localizadas nas bordas de estuários e foz de rios, freqüentemente inundado pelas marés (Andrade \& Lamberti 1965; Andrade 1967; Eiten 1970).

A metodologia de coleta é descrita em Benatti \& Marcelli (2007). O material foi identificado conforme Fink (1905), Galloway (1985) e Hale (1979). Foram realizadas excursões pontuais de coleta a várias localidades urbanas e naturais de todos os municípios da região. O material foi depositado no Herbário Maria Eneyda P. Kauffmann Fidalgo (SP), do Instituto de Botânica, em São Paulo.

Para as análises morfológicas foram observadas características macro e microscópicas dos espécimes, mediante uso de estereomicroscópio e microscópio óptico. Foram analisadas características de estruturas somáticas e de reprodução, tanto direta como indireta, dos talos (Benatti 2005). A metodologia de análises químicas (testes de coloração, irradiação por luz UV e CCD com solvente C) seguiu Asahina \& Shibata (1954), Walker \& James (1980), White \& James (1985), Hüneck \& Yoshimura (1996), Bungartz (2001) e Orange et al. (2001), com pequenas mudanças ou adaptações.

Embora sejam discutidos os aspectos mais relevantes pertinentes a cada uma das espécies encontradas, outras comparações e detalhes podem ser encontrados em Benatti (2005).

\section{Resultados e discussão}

No litoral centro-sul do estado de São Paulo Foram encontradas cinco espécies de Parmotrema contendo ácido stíctico medular e apenas duas contendo ácido equinocárpico. Duas delas foram recentemente descritas (Marcelli et al. 2008) e uma é citação recente para o Estado de São Paulo (Benatti 2005). As outras quatro espécies já foram mencionadas para São Paulo, embora existam apenas um trabalho

\footnotetext{
Instituto de Botânica, Seção de Micologia e Liquenologia, São Paulo, SP, Brasil

Autor para correspondência: michel_benatti@yahoo.com.br
} 
brasileiro e outro em cooperação com pesquisadores alemães contendo chaves e descrições para algumas espécies deste grupo (Eliasaro \& Donha 2003; Fleig et al. 2008).

Três espécies apresentam propagação direta por formação de sorédios [P.dilatatum (Vainio) Hale P. milanezii Marcelli, Benatti \& Elix e P. perlatum (Hudson) M. Choisy], três somente por formação de apotécios [P. eciliatum (Nylander) Hale, P. eliasaroanum Benatti, Marcelli \& Elix e P. lobulatum Marcelli \& Hale) e apenas uma por formação de isídios [P. internexum (Nyl.) Hale ex DePriest \& B. Hale]. Todas as sete espécies são corticícolas ou ramulícolas.

Foram encontrados apotécios maduros contendo ascósporos em alguns espécimes de $P$. dilatatum, $P$. eciliatum, $P$. eliasaroanum e $P$. internexum. Picnídios foram bem mais comuns, embora não tenham sido encontrados conídios somente em espécimes de $P$. perlatum e $P$. milanezii.

Para todas as espécies descritas aqui, os testes de coloração do córtex superior são $\mathrm{K}+$ amarelo (atranorina) e as da medula $\mathrm{K}+$ forte amarelo, $\mathrm{C}-$, e $\mathrm{P}+$ alaranjado (ácidos equinocárpico e stíctico). Algumas das espécies ( $P$. dilatatum e $P$. milanezii) também contêm ácido protocetrárico, que reage $\mathrm{KC}+$ róseo (às vezes alternando para um marrom alaranjado), e talos de $P$. internexum podem apresentar ou não a substância norlobaridona medular, que quando presente reage da mesma forma, apenas com intensidade variável conforme a concentração. Testes corticais em $P$. dilatatum podem eventualmente não reagir fortemente amarelado ao teste $\mathrm{K}$, devido à presença adicional de diferentes concentrações de ácido úsnico junto com a atranorina (o que dá ao córtex uma coloração mais amarelada).

O ácido equinocárpico é encontrado em Parmotrema dilatatum e P. milanezii, sempre acompanhado da presença do ácido protocetrárico, enquanto que o ácido stíctico é a principal substância medular em todas as demais espécies identificadas. $\mathrm{O}$ ácido equinocárpico costuma não reagir com uma coloração amarelada tão forte quanto a do stíctico, e a coloração ocorre de forma mais lenta.

Outras substâncias presentes em menor quantidade na medula dos espécimes foram detectadas e confirmadas por Cromatografia em Camada Delgada (CCD) e nos casos dos espécimes de $P$. dilatatum, $P$. eliasaroanum, $P$. lobulatum e P. milanezii, por Cromatografia Líquida de Alta Performance (CLAP).

Chave artificial de identificação para as espécies de Parmotrema sensu stricto contendo ácidos equinocárpico ou stíctico do litoral centro-sul do Estado de São Paulo

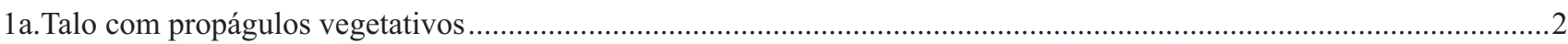

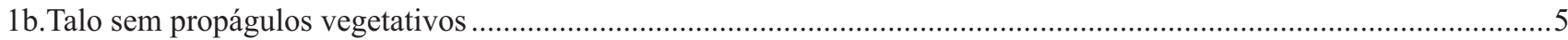

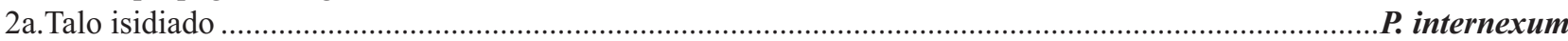

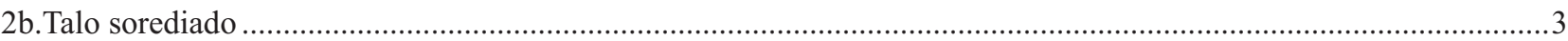

3a. Margens eciliadas, às vezes com cílios simples e escassos restritos às axilas e áreas regeneradas dos lobos [córtex superior com atranorina e ácido úsnico, medula com ácidos equinocárpico e protocetrárico]

P. dilatatum

3b. Margens freqüente a abundantemente ciliadas, cílios simples ou ramificados

\section{4}

4a. Cílios comumente simples, intercalados com os sorais; córtex superior contendo somente atranorina, medula contendo ácido stíctico $(\mathrm{K}+$ prontamente amarelo forte, $\mathrm{KC}-, \mathrm{P}+$ alaranjado).

P. perlatum

4b. Cílios na maioria ramificados, crescendo mesmo em meio aos sorais; córtex superior contendo atranorina e ácido úsnico, medula contendo ácidos equinocárpico e protocetrárico $(\mathrm{K}+$ lentamente amarelo, $\mathrm{KC}+\mathrm{róseo}, \mathrm{P}+\mathrm{alaranjado})$

P. milanezii

5a. Margens inteiras a irregulares (parcialmente sublacinuladas); margens inferiores marrons, tornando-se cremes ou variegadas embaixo dos apotécios.....

P. eciliatum

5b. Margens regularmente muito lobuladas e/ou lacinuladas; margens inferiores uniformemente marrons ou cremes ................ 6

6a. Lobos 1,0-3,0 mm larg.; lacínulas mais subcanaliculadas, formadas freqüentemente a partir dos ápices dos lobos centrais, normalmente eciliadas; pequenos lóbulos marginais abundantes; margem inferior uniformemente marrom; conídios curto filiformes 7,0-9,0 $\mu \mathrm{m}$ comp

P. lobulatum

6b. Lobos 3,0-6,0 mm larg.; lacínulas mais planas, formadas a partir das margens dos lobos, exceto nas partes distais, em geral ciliadas; sem formação de lóbulos; margem inferior geralmente creme (raros trechos distais marrons claros); conídios baciliformes 4,0-8,0 $\mu \mathrm{m}$ comp.

P. eliasaroanum

1. Parmotrema dilatatum (Vainio) Hale, Phytologia 28(4): 335. 1974.

Parmelia dilatata Vainio, Acta Societatis pro Fauna et Flora Fennica 7: 32. 1890.

Figs. 1a-b, 2a-b
Talo lobado a sublobado, cinza esverdeado, cinza amarelado ou verde amarelado, até 22,5 cm diâm, membranáceo a coriáceo, corticícola. Lobos de ramificação irregular, (2,0-) 5,0-15,0 $(-19,0)$ mm larg., contíguos a pouco imbricados a ocasionalmente mais sobrepostos e amontoados no centro do talo, 
306 Benatti \& Marcelli: Espécies de Parmotrema (Parmeliaceae, Ascomycota) do litoral centro-sul do estado de São Paulo III...

pouco adnatos nas partes distais tornando-se mais elevados em direção ao centro às vezes formando dobras pregueadas e subcanaliculadas, adpressos a parcialmente soltos, de ápices arredondados a subarredondados, de subplanos quando mais largos à subcôncavos ou côncavos quando mais estreitos ( $<8,0 \mathrm{~mm}$ larg.), parcialmente elevados, revolutos ou involutos quando sorediados, as margens lisas próximas aos ápices tornando-se subcrenadas ou crenadas, subonduladas, tornando-se mais sinuosas e às vezes involutas ou revolutas quando mais sorediadas, de planas a ascendentes, inteiras $\mathrm{a}$ incisas, às vezes revolutas, curto lacinuladas. Superfície contínua nas partes distais a irregularmente quebrada no centro, as quebras mais acentuadas e quase reticulares em partes mais velhas, lisa a pouco rugosa tornando-se muito rugosa no centro de alguns talos. Lacínulas marginais regulares, curtas, planas, truncadas, 0,3-2,6 x 0,2-2,1 mm, simples ou às vezes furcadas ou irregulares, de lado de baixo concolorido à margem inferior, creme, branco ou negro, às vezes misturadas a lóbulos adventícios jovens arredondados. Máculas ausentes ou às vezes escassas e muito fracas, lineares, laminais, surgindo pela perda de algas em quebras. Cílios normalmente ausentes, às vezes raros e restritos às axilas dos lobos ou bem esparsos pela margem, tipicamente em áreas danificadas regeneradas, $0,2-0,7(-1,5) \mathrm{x}$ ca. 0,05 $\mathrm{mm}$, negros, simples ou ainda mais raro furcados. Sorais capitados a labriformes dispostos nos ápices das lacínulas a lineares interrompidos marginais, tornando-se eventualmente mais coalescentes e irregulares em partes centrais do talo encobrindo parcialmente as lacínulas e aparentando serem lineares contínuos ficando ocasionalmente mais soerguidos (arbusculares?), também ocasionalmente surgindo subcapitados submarginais. Sorédios de farinhosos a subgranulares ou granulares, às vezes grosseiros ou escurecidos. Pústulas e isídios ausentes. Medula branca, normalmente sem pigmentações (um pequeno grupo de espécimes apresentou manchas esparsas de pigmento alaranjado $\mathrm{K}+$ avermelhado escuro, visíveis nos sorais ou na parte inferior da medula). Lado de baixo negro, lustroso, liso a rugoso ou raramente venado, às vezes pouco papilado, esparsamente rizinado. Margem inferior marrom a marrom clara, tornando-se branca, creme ou variegada sob lobos lacinulados e sorediados, lustrosa, $1,0-6,0(-8,5) \mathrm{mm}$ larg., nua, atenuada quando marrom a nítida quando creme ou branca, lisa a pouco rugosa ou pouco venada. Rizinas negras, simples a raramente furcadas ou irregulares, parcialmente aglutinadas, $0,20-0,80(-1,50) \mathrm{x}$ ca. $0,05-0,10(-0,25) \mathrm{mm}$, normalmente escassas sendo às vezes mais freqüentes em algumas partes, agrupadas. Apotécios submarginais comuns, de subcôncavos a subplanos, às vezes tornando-se fendidos e retorcidos quando velhos, 0,4-16,3 mm diâm., subpedicelados, margem lisa e eciliada, tornando-se incisa quando velha e às vezes dobrando, sorediando conforme envelhece, anfitécio liso a pouco rugoso. Disco marrom, não pruinoso, imperfurado, fendido quando velho. Ascósporos elipsóides, (16,0-) 20,0-27,5 x (7,5-) 9,0-12,5 $\mu \mathrm{m}$, epispório $1,5-2,0 \mu \mathrm{m}$. Picnídios ausentes a submarginais freqüentes, às vezes laminais, de ostíolo negro. Conídios lageniformes a sublageniformes curtos, $4,0-7,5 \times$ ca. $1,0 \mu \mathrm{m}$.

Substâncias de importância taxonômica: atranorina e ácido úsnico (córtex superior), ácidos equinocárpico, protocetrárico, subvirênsico, convirênsico, e conequinocárpico (medula).

Material estudado: BRASIL. São Paulo: Bertioga, Praia de São Lourenço, mata de duna posterior no contato com a mata de restinga, 15/XI/1977, M.P.Marcelli \& A.E.Luchi 16333 (SP). Iguape, Barra do Ribeira, entre o "Rio" Suamirim e o oceano, mata de restinga baixa, 17/VII/1989, M.P.Marcelli \& O.Yano 6637 (SP). Ilha Comprida, próximo ao "Villagio", borda da mata de restinga, 02/IV/2004, A.A.Spielmann et al. 1017 (SP); idem, parte central da ilha, próximo ao "Villagio", local loteado com algumas casas construídas, 2/IV/2004, M.N.Benatti et al. 1738 (SP); idem, restinga baixa próxima à balsa para Cananéia, 2/IV/2004, A.A.Spielmann et al. 808, 812, 813, 822, 823, idem, 4/ IV/2004, A.A.Spielmann et al. 953, 956, 957, 958, 959, 961, 1104 (SP); idem, à beira da estrada próximo à balsa para Cananéia, mata de restinga baixa, 2/IV/2004, L.S.Canêz, et al. 1288, 1297, 1310, 1343, 1346, (SP); idem, 3/IV/2004, L.S.Canêz et al. 1236, 1238, 1239, 1268, 1272 (SP); idem, 2/IV/2004, M.N.Benatti et al. 1752, 1761 (SP); idem, parte sul da ilha, próximo à balsa para Cananéia, mata de restinga baixa à algumas centenas de metros da balsa, 2-IV-2004, M.N.Benatti et al. 1754A; idem, 3/IV/2004, M.N.Benatti et al. 1765, 1771, 1774, 1781, 1790, 1799, 1802 (SP); Itanhaém, manguezal na margem direita do Rio Itanhaém, próximo à ponte na Rodovia Padre Manoel da Nóbrega (SP-55) km 108, 10/I/1979, M.P.Marcelli \& L.R.Fontes 1578, 1722, 1723 (SP); idem, 28/I/1982, M.P.Marcelli \& J.Vieira Filho 1724 (SP); idem, 15/X/2003, A.A.Spielmann et al. 533, $537 a, 537 b(\mathrm{SP})$; idem, no manguezal próximo à ponte do Rio Itanhaém, 15/X/2003, L.S.Canêz et al. 532 (SP); idem, 15/X/2003, M.N.Benatti et al. 1639 (SP); idem, $15 / \mathrm{X} / 2003$, M.R.Käffer et al. s.n. (3 coletas) (SP); idem, 15/X/2003, S.B.Barbosa et al. s.n. (SP); idem, nas proximidades do Rio Preto, ca. 2,5 Km da Praia de Itanhaém, atrás da CESP, na Rua Las Vegas, 23/V/1994, M.P.Marcelli \& A.E.Luchi 27208 (SP); idem, Balneário Santa Cruz, próximo à divisa de municípios entre Itanhaém e Peruíbe, mata de restinga baixa ca. $500 \mathrm{~m}$ da praia, terrenos baldios em área loteada, 14/I/2004, M.N.Benatti et al. 1689, 1690, 1704, 1715, 1716, 1720, 1725 (SP); idem, ca. $300 \mathrm{~m}$ do oceano, mata de restinga baixa, 10/II/2004, M.P.Marcelli, et al. 36213, 36201, 36218, 36223, 36226, 36229, 36231, 36272 (SP). Mongaguá, próximo à estação de tratamento de água da SABESP no Rio Bichoró, mata de restinga baixa próxima às margens do Rio Bichoró, 15/XII/2003, M.N.Benatti \& M.P.Marcelli 1649, 1650, 1654B, 1674A (SP). Peruíbe, margem do Rio Guaraú, manguezal na beira do rio, 23/VII/1988, M.P.Marcelli \& 
O.Yano 3903, 3915 (SP). Praia Grande, Bairro Cidade Ocean, ca. $1 \mathrm{Km}$ da estátua de Iemanjá, $2 \mathrm{Km}$ da de Netuno, em direção à Mongaguá, terreno entre a praia e a estrada com resíduo de mata de duna posterior e mata de restinga, 6/ VII/1988, M.P.Marcelli \& J.Vieira Filho 3024 (SP); idem, Jardim Real, em terreno baldio na zona urbana ca. 1,5 Km da praia, 15/XII/2003, M.N.Benatti \& M.P.Marcelli 1684 (SP). São Sebastião, Centro de Biologia Marinha (CEBIMAR) da USP, a $10 \mathrm{~m}$ da praia, 18//II/1988, M.P.Marcelli 2192, 2195, 2196 (SP). Ubatuba, Ilha Anchieta, mata de restinga, próximo ao arroio no interior da mata, 23/XI/2003, L.S.Canêz \& A.A.Spielmann 649 (SP).

Distribuição: Pantropical. Oceania, Ásia, África, América do Norte, América Central e América do Sul. Brasil: AM(?), GO, MG, MS, MT, PA, RS, SC, SP (Hale 1965; Krog \& Swinscow 1981; Brako et al. 1985; Swinskow \& Krog 1988; Fleig \& Riquelme 1991; Marcelli 1992; Osorio 1992; Fleig 1997; Galloway \& Quilhot 1998; Sipman 2000; Feuerer 2008; Benatti 2005).

Comentários: Foram aceitos neste trabalho como espécimes de $P$. dilatatum os que se encaixaram dentro da variabilidade mais característica citada em literatura. Assim sendo, os espécimes aqui descritos são caracterizados pelos lobos largos e subarredondados, margens eciliadas ou raramente esparso-ciliadas com cílios curtos e simples, sorais comumente marginais nos ápices de lacínulas curtas ou lineares interrompidos, lado de baixo esparsamente rizinado, córtex superior contendo quantidades variáveis de ácido úsnico junto com atranorina e medula contendo sempre os ácidos equinocárpico e protocetrárico.

Comparando os espécimes de nossa localidade de estudo às descrições de espécimes de Parmotrema dilatatum em diversos trabalhos (Vainio 1890; Hale 1965; Moore 1968; Awasthi 1976; Krog \& Swinscow 1981; Galloway 1985; Swinscow \& Krog 1988; Fleig 1997; Ribeiro 1998; Louwhoff \& Elix 1999; Brodo 2001; Eliasaro 2001; Kurokawa \& Lai 2001; Donha 2005), concluiu-se que a circunscrição da espécie ainda é confusa. Esta precisa ser esclarecida e $P$. dilatatum separada de outras espécies semelhantes, mas que têm sido confusamente identificadas pelo mesmo nome, formando um grupo que seria melhor compreendido como "complexo Parmotrema dilatatum". Mais esclarecimentos, contudo, só poderão ser conseguidos com mais dados, provenientes de material de mais localidades, de análises cromatográficas e químicas com comparações morfológicas e com o estudo dos tipos da espécie, de seus sinônimos e de outras espécies próximas.

Marcelli (1991) relatou dificuldade em lidar com o grupo de espécies de Parmotrema de margens sorediadas da costa sudeste do Estado de São Paulo, que normalmente caiam no complexo de $P$. gardneri (Dodge) Sérusiaux, (espécie próxima à $P$. dilatatum), citando que distinguia 13 grupos morfobiológicos a partir de seu material estudado, incluin- do espécies como $P$. chinense, $P$. dilatatum, $P$. mordenii, $P$. praesorediosum e $P$. subarnoldii (todos estes encontrados em nossa localidade de estudo) e outras que não pôde identificar à época, algumas descobertas como novas para a ciência (Marcelli et al. 2008).

À exceção de Parmotrema madilynae Fletcher (Benatti 2005), nenhuma outra espécie da localidade de estudo apresentou tanta variedade morfológica e tantos aparentes estágios intermediários quanto $P$. dilatatum. Foi encontrada uma variação tão grande de caracteres vegetativos e de reprodução, que ao consultar a bibliografia e comparar os dados obtidos, tornou-se difícil compreender a espécie. A composição química também apresentou diversos intermediários, os espécimes apresentando quantidades variáveis ou mesmo ausência ocasional de uma ou outra substância. A literatura consultada apresenta uma variação de caracteres não encontrada para nenhuma outra espécie de Parmotrema encontrada na localidade de estudo (Tab. 1).

Foram bastante raros os espécimes com cílios marginais, estes esparsos, simples e muito curtos, restritos a algumas partes do talo. Louwhoff \& Elix (1999) mencionam que a ocorrência destes pode estar na verdade subordinada à ação predatória de insetos que devoram parte das margens, que se regeneram.

Há espécies com hábito e disposição de sorais similares, mas que podem ser distinguidas, principalmente pela composição química: $P$. robustum (Degelius) Hale tem lobos menos lacinulados, sorais menos contínuos, e apresenta somente o ácido protocetrárico, sem ácido equinocárpico na medula (Fleig 1997). Parmotrema subochraceum Hale tem talo sempre membranáceo, contendo também somente ácido protocetrárico medular e possui um característico padrão de pigmentação alaranjada $\mathrm{K}+$ vermelho escura em parte das hifas, visíveis na porção inferior da medula Parmotrema subarnoldii (Abbayes) Hale tem margens bem ciliadas, com cílios longos e sorais marginais lineares mais contínuos e com sorédios mais farinhosos, um tanto quanto parecida com P. sancti-angeli (Lynge) Hale, e também apresenta somente ácido protocetrárico medular (Benatti 2005).

Dentre as espécies com morfologia próxima, porém química medular totalmente diferente, $P$. cristiferum (Taylor) Hale difere por ser bem pouco sublacinulada, com sorais mais marginais, e possuir ácidos salazínico e consalazínico como constituintes químicos medulares. Já $P$. praesorediosum (Nylander) Hale tem o córtex superior sem os ácidos úsnico ou isoúsnico, sorais marginais lineares mais finos e contínuos do tipo labriformes ou em formato de crescente, não forma lacínulas pelas margens tem os sorais, é sempre eciliada, e não apresenta reações de coloração na medula devido à presença somente de ácidos graxos (Benatti 2005).

Parmotrema perlatum (Hudson) M. Choisy difere pela presença constante de cílios marginais, pelo formato e disposição típicos dos sorais (ver os comentários sobre esta espécie), pelo córtex inferior densa e homogeneamente rizinado, e pela presença de ácido stíctico medular. 


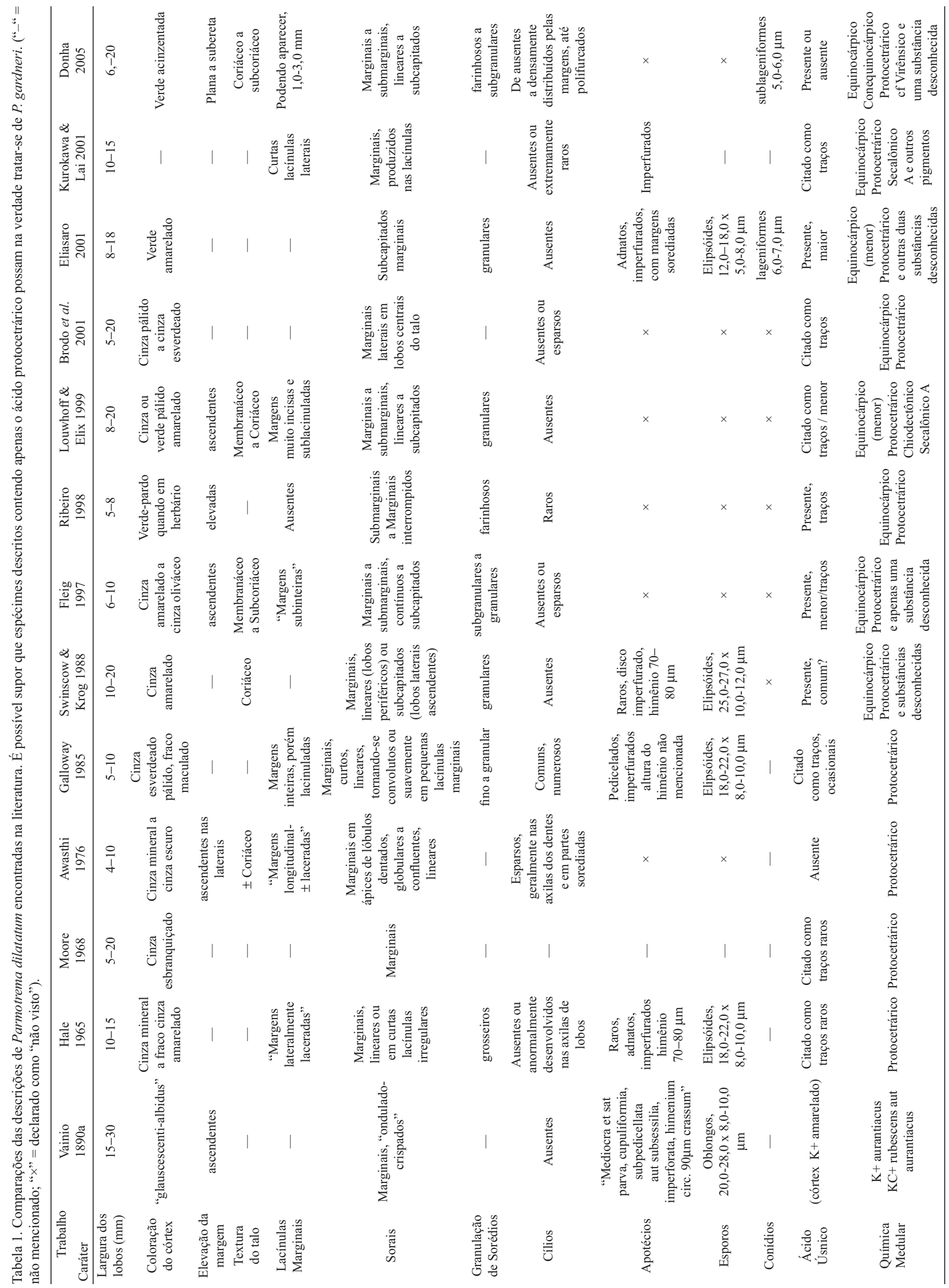


Parmotrema milanezii Marcelli, Benatti \& Elix, uma espécie próxima recém descrita e que contém praticamente a mesma composição química medular de P. dilatatum (Marcelli et al. 2008), difere pelos talos sempre membranáceos com formação de cílios marginais abundantes, freqüentemente muito ramificados, e que surgem até mesmo dos sorais (onde são destacáveis dos sorédios).

Uma espécie descrita para o Hawaii, Parmelia kanaiiensis Zahlbruckner (Magnusson \& Zahlbruckner 1944), foi sinonimizada por Hale (1965) em Parmelia dilatata (=Parmotrema dilatatum). A descrição desta espécie é próxima da de $P$. dilatatum, incluindo a disposição e o formato dos sorais, contudo os autores mencionam que não viram apotécios ou picnídios no material, e citam apenas reações químicas negativas na medula, o que poderia indicar a provável ausência dos ácidos equinocárpico e protocetrárico, responsáveis pelas reações positivas dos testes de coloração em P. dilatatum.

Pela literatura, P. gardneri (Dodge) Sérusiaux é a espécie mais conflitante quanto aos aspectos da morfologia e da química quando comparada com $P$. dilatatum, demonstrando semelhanças também quanto à algumas características taxonômicas, mas difere pelos lobos mais estreitos e pelos sorais mais finos, também apresentando somente o ácido protocetrárico sem o equinocárpico na medula (Dodge 1959; Swinscow \& Krog 1988; Fleig 1997; Ribeiro 1998; Benatti 2005). Estas duas espécies diferem principalmente pela química medular e pelo tamanho dos ascósporos $(\leq 22,0$ $\mu \mathrm{m}$ em $P$. gardneri e $\geq 20,0 \mu \mathrm{m}$ em $P$. dilatatum, conforme as descrições que melhor diferem as espécies).

Com a confusão que existe no emprego do nome $P$. dilatatum para quase qualquer espécime de Parmotrema que seja marginalmente sorediada, eciliada ou esparsamente ciliada, e que apresente os testes de coloração $\mathrm{K}+$ amarelo e $\mathrm{P}+$ alaranjado, é possível afirmar com base nas descrições encontradas que há possibilidade de que material citado em diversos trabalhos na literatura contendo apenas o ácido protocetrárico medular, ou não cromatografado, possa ter sido confundido com P. dilatatum (Hale 1965; Moore 1968; Awasthi 1976; Galloway 1985), mas que se tratem na verdade P. gardneri. (Dodge) Sérusiaux, que tem talo coriáceo, margens eciliadas e sorediadas com disposição semelhante de sorais, e que apresenta reações químicas quase idênticas, ou mesmo ainda que se trate de outra espécie.

A maioria dos autores que menciona $P$. gardneri em seus trabalhos considera o talo como coriáceo, à exceção de Brodo et al. 2001, que diferiu $P$. gardneri de $P$. dilatatum por ser mais fina e ter lobos mais estreitos - em geral menores que $6,0 \mathrm{~mm}$, além da ausência do ácido equinocárpico. Os conídios são similares nas duas espécies e com medidas equivalentes, variando de sublageniformes a lageniformes, medindo entre 4,0-7,0 $\mu \mathrm{m}$ (Swinscow \& Krog 1988).

Poucos espécimes de $P$. dilatatum analisados apresentaram pigmento alaranjado $\mathrm{K}+$ na medula, (citado em algumas descrições de P. gardneri). Estes fazem parte de um subgrupo com talos mais membranáceos (ver comentários adiante).
Os espécimes de $P$. dilatatum estudados que possuem talos coriáceos (mais próximos na morfologia à $P$. gardneri) são sempre eciliados. Assim como também ocorre com $P$. dilatatum, cílios axilares esparsos são também citados em algumas descrições de P. gardneri (Dodge 1959, Krog \& Swinscow 1981, Sérusiaux 1984, Swinscow \& Krog 1988, Elix 1994, 2001, Louwhoff \& Elix 1998, Ribeiro 1998, Brodo et al. 2001).

Hale (1965) afirmou que havia examinado o material tipo de $P$. dilatatum, mas citou ascósporos menores que os mencionados por Vainio (1890) na descrição original. Hale (1965) também afirmou erroneamente que o material não reagia ao teste $\mathrm{K}$ medular, e não mencionou a presença do ácido equinocárpico na medula, sendo que segundo Hale havia sido encontrado somente ácido protocetrárico. Porém isto explica porque Hale (1965) aceitou tantas espécies diferentes na sinonímia de $P$. dilatatum.

A Tabela 1 mostra as variações encontradas na literatura, observando-se algumas diferenças mais notáveis entre os espécimes: lobos mais estreitos (com $1,0 \mathrm{~cm}$ ou menos) ou mais largos (com 1,0-2,0 cm ou às vezes até mais), com graus variados de adnação, elevação e sinuosidade das margens; espessura e textura do talo variando de membranácea a subcoriácea; sorais que vão de escassos em ápices de lacínulas à muito abundantes até marginais, com sorédios que variam de granulação, de quase farinhosos, passando por subgranulares a granulares e grosseiros; quantidade inconstante de lacínulas nas margens, quase ausentes a abundantes em alguns espécimes; tamanho dos esporos que variam de 12,0-15,0 (-18,0) (Eliasaro 2001) a até 20,0-28,0 (Vainio 1890a) ou 25,0-27,0 (Swinscow \& Krog 1988), e ausência mesmo de traços de ácido úsnico em vários espécimes.

Todas estas variações das descrições encontradas em literatura (Vainio 1890a; Hale 1965; Moore 1968; Awasthi 1976; Galloway 1985; Swinscow \& Krog 1988; Fleig 1997; Ribeiro 1998; Louwhoff \& Elix 1999; Brodo 2001; Eliasaro 2001; Kurokawa \& Lai 2001; Donha 2005) puderam ser notadas no material aqui analisado, e mais algumas citadas que foram vistas somente neste trabalho.

Há ao menos dois grupos reconhecíveis no material de $P$. dilatatum estudado: um é caracterizado pelos talos mais coriáceos, sempre bastante cinzentos, com sorais mais freqüentemente marginais lineares do que dispostos em lacínulas, e sorédios mais granulares; já o segundo grupo tem talos planos e membranáceos, córtex superior bastante quebrado, sorais em sua maioria capitados a labriformes nos ápices de lacínulas marginais, sorédios mais farinhosos, e medula branca com manchas ocasionais de pigmento alaranjado $\mathrm{K}+$ vermelho escuro (geralmente mais visíveis nos sorais). Este segundo grupo tem os lobos de largura menor, 3,0-7,0 (-11,0) mm. Vários dos espécimes estudados não se encaixam bem em nenhum destes grupos, apresentando ainda outras variações.

Dentre as nuanças observadas nos sorais, existem espécimes com sorais mais largos, aparentando um formato 
labriforme, porém mais extenso, devido a fundirem-se ao longo das margens e se tornando mais lineares ou mais irregulares em direção ao centro do talo. Alguns talos apresentam sorais mais irregulares e ascendentes (arbusculares?) principalmente nas partes velhas centrais.

Notou-se no material do grupo de espécies de talos mais coriáceos que há espécimes com sorais totalmente claros e outros em que os sorais são inicialmente claros e vão se tornando escuros em direção ao centro velho. Esta impressão é devido à exposição da margem inferior dos lobos que, junto a alguns sorais, é geralmente negra (diferente do que é comum em outras espécies do gênero) e ligeiramente revoluta. Esse parece ser um fato um tanto quanto corriqueiro, embora surja apenas em certo estágio do desenvolvimento dos sorais.

\section{Parmotrema eciliatum (Nylander) Hale, Phytologia} 28(4): 336. 1974.

Parmelia crinita var. eciliata Nylander, Flora 52: 291. 1869. Fig. 3a-b

Talo sublobado, cinza esverdeado, de até 19,0 cm diâm., subcoriáceo, ramulícola ou corticícola. Lobos de ramificação irregular, 2,0-8,0 mm larg., contíguos a imbricados ou parcialmente amontoados quando corticícolas, mais sobrepostos e amontoados quando ramulícolas, pouco adnatos a elevados, pouco adpressos a soltos, os ápices subarredondados a irregulares, subplanos a subcôncavos, as margens crenadas a irregulares, subonduladas, subplanas a elevadas, inteiras a incisas, parcial e irregularmente sublacinuladas. Superfície contínua a irregularmente quebrada, de lisa a rugosa, às vezes bastante enrugada em alguns lobos. Lacínulas marginais ausentes a esparsa e irregularmente distribuídas, curtas, planas, truncadas ou às vezes agudas, $0,3-2,5(-6,7) \times 0,2-1,0(-2,3)$ $\mathrm{mm}$, simples quando bem pequenas tornando-se irregularmente ramificadas ou retornando ao formato de lobos quando maiores, em geral mais comuns no centro velho do talo, às vezes misturadas a lóbulos jovens irregulares, lado de baixo concolorido à margem inferior. Máculas ausentes a escassas, lineares fracas laminais ou às vezes distintas quando nos anfitécios. Cílios marginais abundantes, negros, 0,1-2,3 x ca. $0,05 \mathrm{~mm}$, simples a raramente furcados. Sorais, pústulas e isídios ausentes. Medula branca, sem pigmentações. Lado de baixo negro, lustroso, liso a rugoso, às vezes pouco papilado na transição para as margens, moderadamente rizinado. Margem inferior marrom a creme, às vezes variegada, lustrosa, 0,5-4,0 $\mathrm{mm}$ larg., nua, atenuada quando marrom a nítida quando creme, lisa tornando-se pouco papilada na transição para o centro. Rizinas negras, simples a furcadas ou irregulares, $0,20-1,20(-2,60) \times$ ca. $0,05 \mathrm{~mm}$, escassas a freqüentes ou raramente abundantes, de agrupadas em algumas partes a homogeneamente distribuídas em outras. Apotécios côncavos a cupuliformes, 0,4-11,0 mm diâm., de submarginais a subapicais ou raramente laminais, pedicelados, pedicelos em parte inflados quando subapicais, as margens crenadas a denteadas às vezes com pequenos lóbulos, anfitécios e pedicelos lisos quando jovens a rugosos quando velhos, às vezes venados na junção do pedicelo com o disco. Disco marrom, não pruinoso, imperfurado, às vezes fendido, retorcido ou involuto quando velho. Ascósporos elipsóides, (16,0-) 19,0-28,0 (-36,0) x (10,0-) 12,0-17,0 $\mu \mathrm{m}$, epispório $2,0-3,0(-4,0) \mu \mathrm{m}$. Picnídios submarginais comuns, às vezes avançando sobre a lâmina, de ostíolo negro. Conídios baciliformes a filiformes curtos, 5,0-9,0 $(-10,0)$ x ca. $1,0 \mu \mathrm{m}$.

Substâncias de importância taxonômica: atranorina (córtex superior), ácido stíctico e traços de outros ácidos do complexo stíctico (medula).

Material estudado: BRASIL. Rio de Janeiro: Magaratiba, Vila Itacuruçá, manguezal, 16/V/1982, Marcio s.n. (SP). São Paulo: Peruíbe, margem esquerda do Rio Guaraú, manguezal na beira do rio, 23/VII/1988, M.P. Marcelli \& O.Yano 3916, 3922, 3924, 3925, 3926, 3931 (SP). Iguape, Barra do Ribeira, entre o "Rio" Suamirim e o oceano, mata de restinga baixa, 18/VII/1989, M.P.Marcelli \& O.Yano 6692, 6693, 6708, 6846, 6848 (SP).

Distribuição conhecida: Pantropical. Oceania, Ásia, África, América do Norte, América Central e América do Sul. Brasil: RJ, RS, PR e SP (Hale 1965; Osório et al. 1980; Krog \& Swinscow 1981; Swinscow \& Krog 1988; Elix 1994; Donha 2005; Benatti 2005; Canêz 2005; Spielmann 2005).

Comentários: Esta espécie é caracterizada pela ausência de propágulos vegetativos, margens ciliadas, apotécios crenados a denticulados eciliados (razão do epíteto específico) e presença de ácidos stíctico, constíctico e conorstíctico na medula ( $\mathrm{K}+$ amarelo, $\mathrm{P}+$ alaranjado, $\mathrm{UV}-$ ).

A variedade morfologica encontrada em nossa localidade de estudo é praticamente a mesma observada por Fleig (1997) para seus espécimes do Rio Grande do Sul: os talos que crescem em ramos tendem a ter lobos mais elevados e amontoados e a formarem apotécios com mais freqüência, enquanto que os que crescem em córtices arbóreos são mais planos e estendidos, raramente formando apotécios.

É comum que as margens inferiores dos talos corticícolas sejam com mais freqüência castanhas (lobos com apotécios são na maioria cor de creme no lado de baixo, mas estes são comumente escassos ou ausentes). Outra observação de Fleig (1997) que diz respeito à variação do tamanho dos ascósporos num mesmo apotécio ou em apotécios de mesmo tamanho de um mesmo indivíduo foi também observada aqui, sendo que em alguns apotécios de um dos espécimes estudados foram encontrados ascósporos $24,0-36,0 \mu \mathrm{m}$, maiores que a média geral obtida nos demais espécimes ou mesmo em outros apotécios do mesmo talo, ainda que dentro da média geral. Nenhum outro caráter morfológico ou químico deste espécime mostrou ser diferente dos demais estudados. 


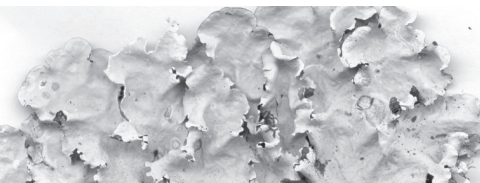

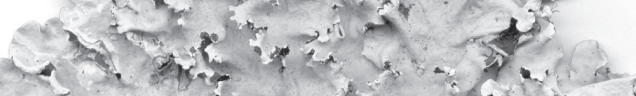

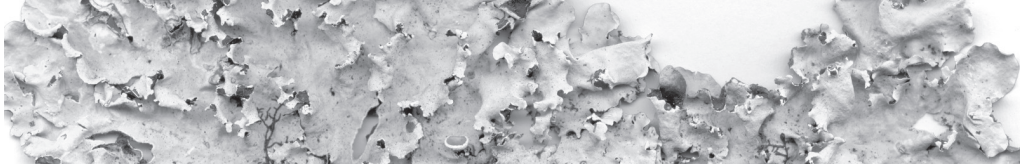

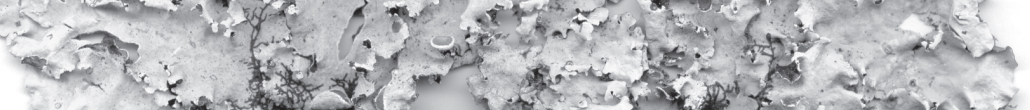

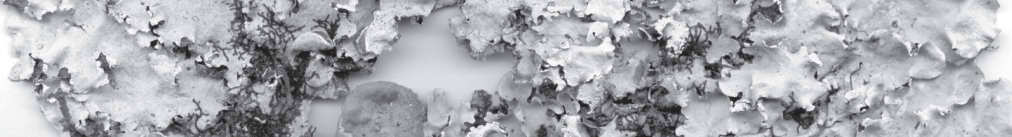

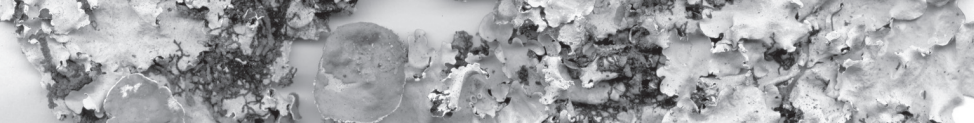

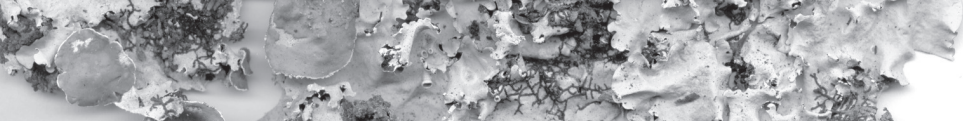

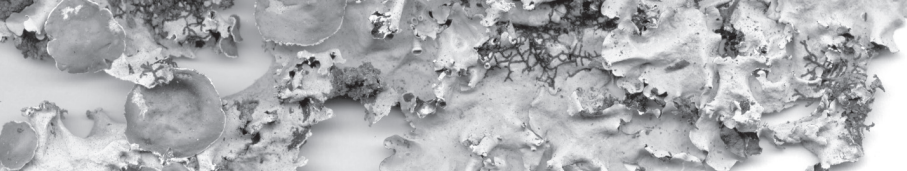

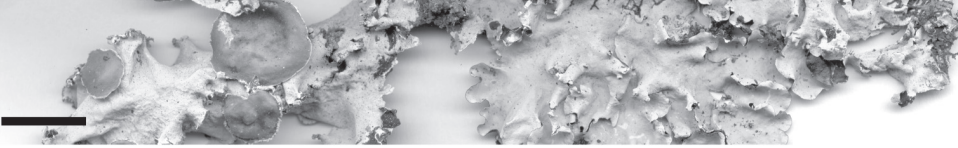

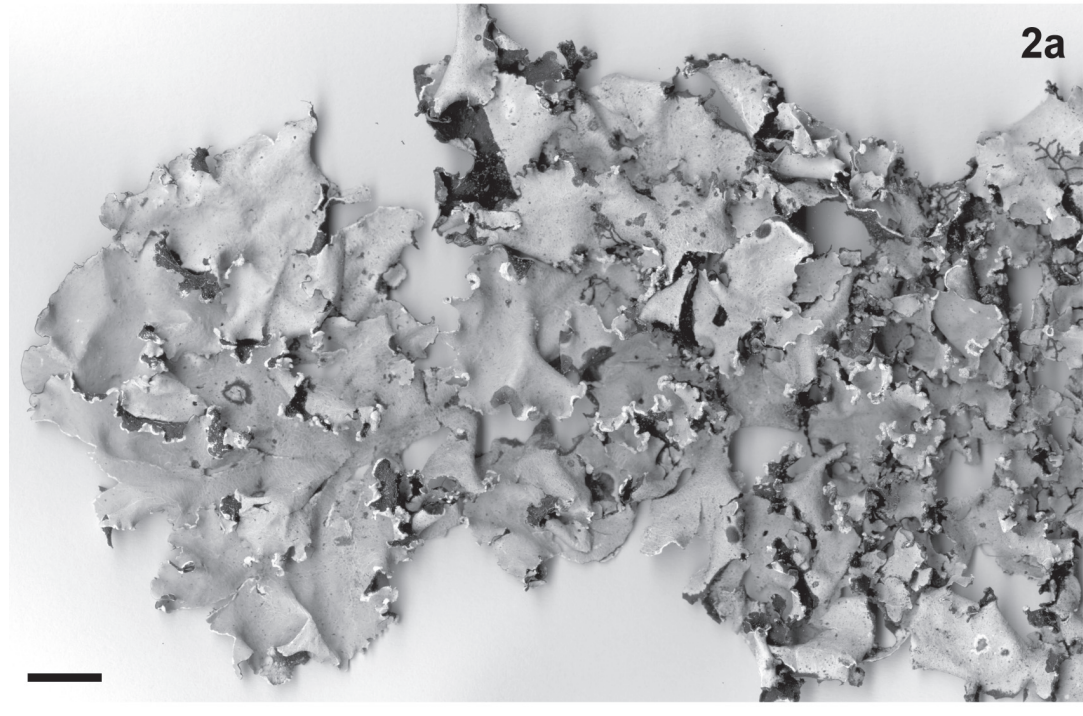

$2 a$

(1)

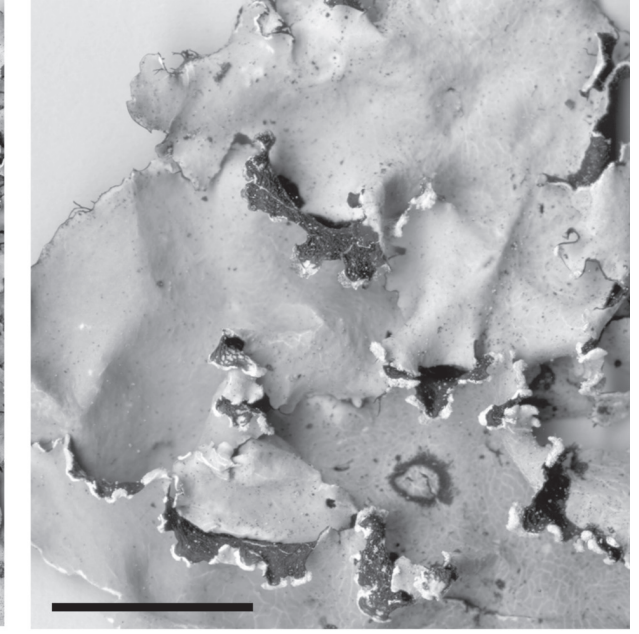

$\rightarrow x+x^{-1}+x^{2}-3 a$

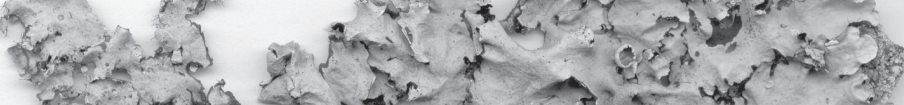

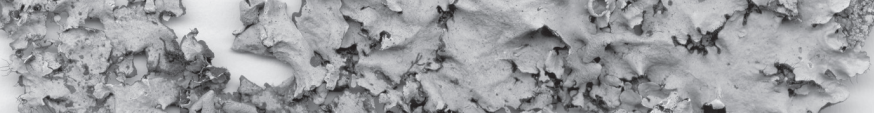

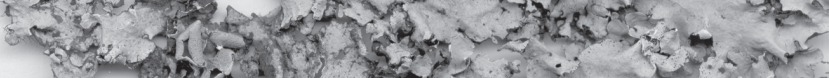

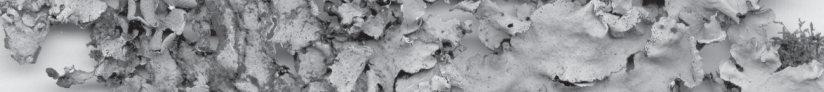
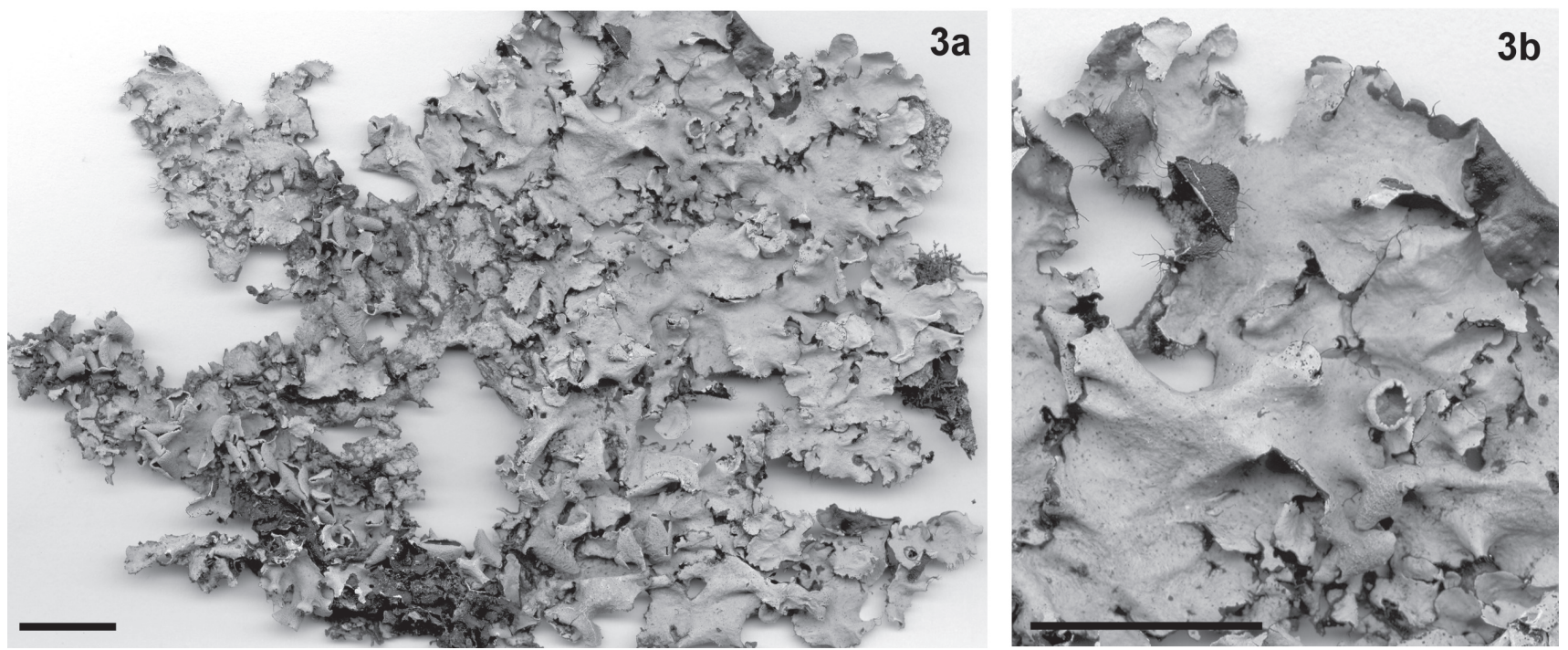
Um dos espécimes analisados tem lobos venados em várias partes distais, é quase eciliado, e em CCD demonstrou conter o que aparenta ser ácido criptostíctico, com ausência do que aparenta ser ácido conorstíctico. O espécime tem poucos apotécios jovens sem ascos ou de himênio enegrecido. Parece tratar-se de um espécime depauperado de P. eciliatum, entretanto a diferença na composição química secundária, a rugosidade venosa de parte dos lobos e a escassez de cílios marginais deixam algumas dúvidas se realmente este espécime pode ou não se tratar de uma variedade desta espécie.

Parmotrema lobulatum Marcelli \& Hale difere pelos talos com margens regularmente lobuladas com vários pequenos lóbulos de no máximo $0,5 \mathrm{~mm}$ comp., lobos centrais freqüentemente canaliculando-se e tornando-se lacinulados, e margens inferiores sempre marrons. Parmotrema eliasaroanum Benatti \& Marcelli tem as margens regular e densamente lacinuladas com lacínulas planas a subplanas e ciliadas (exceto em alguns dos lobos distais), e margens inferiores quase uniformemente da cor creme, mesmo em vários dos lobos distais não lacinulados (ver mais comentários sobre estas espécies).

\section{Parmotrema eliasaroanum Benatti, Marcelli \& Elix,} Mycotaxon 105: 236. 2008.

Fig. 4a-b

Talo lobado a sublobado, verde acinzentado, de até $15,0 \mathrm{~cm}$ diâm., ramulícola. Lobos de ramificação irregular, (2,0-) 3,0-6,0 mm larg., de contíguos a pouco imbricados, adnatos e adpressos, tornando-se um pouco mais amontoados, de elevados e mais soltos conforme se tornam lacinulados, os ápices subarredondados ou irregulares, as margens lisas, subcrenadas ou irregulares, de planas a subplanas, parcialmente subonduladas, inteiras a incisas, regularmente lacinuladas. Superfície contínua a pouco irregularmente quebrada, lisa. Lacínulas originadas principalmente das margens e às vezes dos ápices dos lobos, de formato regular, freqüentes a mais abundantes nas partes velhas centrais, às vezes um pouco amontoadas, ciliadas, de planas a subplanas, $0,4-5,6 \times 0,2-1,2 \mathrm{~mm}$, truncadas a subtruncadas, simples a dicotômicas anisotômicas ou irregulares, lado de baixo creme ou às vezes variegado. Máculas ausentes. Cílios marginais negros, simples, $0,2-1,5(-2,3) \times$ ca. $0,05 \mathrm{~mm}$, freqüentes, incluindo nas lacínulas. Sorais, pústulas e isídios ausentes. Medula branca, sem pigmentações. Lado de baixo negro, lustroso, de liso a pouco rugosas, papilado, os trechos que não tocam o substrato não sendo rizinados. Margem inferior creme, às vezes variegada, raramente marrom em alguns poucos lobos jovens distais, lustrosa a opaca, 1,0-5,5 mm larg., nua, nítida quando creme ou marrom mesmo em lobos pouco ou não lacinulados, às vezes também atenuada quando marrom, lisa a pouco rugosa. Rizinas negras, simples, $0,10-1,30 \times$ ca. $0,05 \mathrm{~mm}$, de poucas a freqüentes ou às vezes mais abundantes em alguns poucos trechos, agrupadas nas partes do córtex inferior que tocam o substrato. Apotécios submarginais a subterminais, côncavos tornando-se fendidos e involutos quando velhos, , 0,8-6,0 mm diâm., pedicelados, margem crenada a lacinulada-denticulada eciliada, anfitécio e pedicelo lisos. Disco marrom, não pruinoso, imperfurado. Ascósporos elipsóides, 22,5-29,0 x 12,5-15,0 $\mu \mathrm{m}$, epispório $3,0-4,0 \mu \mathrm{m}$. Picnídios submarginais comuns, mais abundantes nas lacínulas, de ostíolo negro. Conídios baciliformes a curto filiformes, $4,0-8,0 \mathrm{x}$ ca. $1,0 \mu \mathrm{m}$.

Substâncias de importância taxonômica: atranorina (córtex superior), ácidos stíctico, metil stíctico, constíctico, criptostíctico e peristíctico (medula).

Material estudado: BRASIL. São Paulo: Cananéia, Ilha do Cardoso, restinga da Vila Marujá, mata de restinga baixa pós dunas no interior da ilha, 21/X/1981, M.P.Marcelli 1757 (holótipo, SP). Iguape, Barra do Ribeira, entre o "Rio" Suamirim e o oceano, mata de restinga na beira do manguezal, 18/VII/1989, M.P.Marcelli \& O.Yano 6857 (SP).

Distribuição conhecida: América do Sul. Brasil: SP (Benatti 2005; Marcelli et al. 2008).

Comentários: Parmotrema eliasaroanum caracteriza-se pelo talo adnato com lobos lacinulados elevados, margens ciliadas com lacínulas planas a subplanas dicotômica e irregularmente ramificadas, ausência de propágulos vegetativos, margem inferior quase totalmente da cor creme, rizinas freqüentes e agrupadas, e apotécios lacinulados-denticulados eciliados.

A princípio esta espécie foi suposta tratar-se de Parmotrema lobulatum Marcelli \& Hale, antes que o isótipo e um topotipo desta espécie fossem examinados. Ao comparar os espécimes foi possível estabelecer diferenças consistentes entre as duas espécies: P. lobulatum tem talo mais solto e elevado, de lobos mais estreitos (normalmente 1-3 mm larg.) que os de P. eliasaroanum, suas lacínulas variam de planas a subcanaliculadas e são mais irregulares no formato e no padrão de ramificação, originando-se mais dos ápices dos lobos centrais do que pela margem em geral, sendo sempre eciliadas. Além disto, uma grande quantidade de pequenos lóbulos procumbentes forma-se visivelmente por toda a margem do talo de P. lobulatum (inclusive nas margens das próprias lacínulas), e que dão o nome a esta espécie.

Como outras diferenças encontradas, as margens inferiores em $P$. lobulatum são sempre marrons, mesmo nos lobos lacinulados, e muito estreitas; as rizinas são mais homogeneamente distribuídas, ainda que poucas e esparsas; os conídios também são em média maiores que os de P. eliasaroanum, medindo 7,0-9,0 $\mu \mathrm{m}$ comp.; e a medula apresenta uma composição diferente de ácidos medulares secundários, vistos em CCD/CLAP comparando diretamente as amostras das duas espécies, que em $P$. lobulatum, além do ácido stíctico, apresenta como substâncias não encontradas em P. eliasaroanum os ácidos menegaziaico, hipostíctico, e substíctico, além de ausência do ácido metil stíctico. A 
concentração do ácido peristíctico é também maior em $P$. lobulatum, tendo sido detectados apenas traços da substância em P. eliasaroanum.

Dentre as espécies similares a $P$. eliasaroanum encontradas na localidade de estudo, Parmotrema zicoi Marcelli \& Ribeiro (Marcelli \& Ribeiro 2002, Benatti 2005) diferenciase pelas lacínulas marginais e apicais muito mais longas (até 25,0 mm), subcanaliculadas e de ápices planos (em forma de espátula), na presença de máculas no córtex e nos apotécios, conídios baciliformes menores medindo entre 3,0-5,0 $\mu \mathrm{m}$, margem inferior marrom clara a branca ou variegada sem uma coloração predominante e pela presença de ácido protocetrárico na medula. Parmotrema zicoi tem ascósporos de tamanho similar aos de $P$. eliasaroanum, alguns ligeiramente maiores $(-32,0 \mu \mathrm{m})$, porém com epispórios bem menos espessos $(1,0-1,5 \mu \mathrm{m})$.

Parmotrema merrillii (Vainio) Hale (=Parmelia merrillii, Vainio 1909; Hale 1965) difere pelos lobos mais largos $(10,0-15,0 \mathrm{~mm})$, margens esparsamente ciliadas, apotécios ciliados de anfitécio rugoso e maculado com lacínulas mais longas (denteado-lacinulados), coloração marrom constante nas margens inferiores, rizinas mais esparsas, ascósporos em média maiores (26,0-34,0 $\mu \mathrm{m}$ comp.), e presença de ácido protocetrárico na medula.

Segundo Louwhoff \& Elix (1999) e conforme o material encontrado no litoral (Benatti 2005), Parmotrema elacinulatum (Kurokawa) Streimann assemelha-se à $P$. eliasaroanum, diferindo desta espécie pelas margens não lacinuladas (os espécimes deste trabalho são parcialmente sublacinulados, com lacínulas simples muito curtas, devido ao recorte um tanto irregular das margens), pela presença de ácido protocetrárico medular e pelos cílios mais longos (entre 1,0-3,0 $\mathrm{mm}$, algumas vezes maiores). Elix (1993) mencionou para P. elacinulatum (como o sinônimo P. submerrillii) conídios sublageniformes pequenos, medindo 5,0-6,0 $\mu \mathrm{m}$ compr., similares aos dos espécimes vistos por Benatti (2005).

\section{Parmotrema internexum (Nylander) Hale ex DePriest \&}

B. Hale, Mycotaxon 67: 204. 1998.

Parmelia internexa Nylander, Flora 69 (24): 609. 1885.

Fig. 5a-b

Talo lobado a sublobado, cinza esverdeado, até $15,5 \mathrm{~cm}$ diâm., submembranáceo, ramulícola ou corticícola. Lobos de ramificação irregular, 1,5-4,5 $(-8,0)$ mm larg., contíguos ou às vezes um pouco imbricados em direção ao centro, adnatos, adpressos, às vezes formando muitas dobras, os ápices subarredondados, de planos a subplanos, as margens lisas ou tornando-se subcrenadas pelo surgimento de isídios, subonduladas, de subplanas a subascendentes e às vezes um pouco involutas, inteiras. Superfície contínua, às vezes com poucas quebras em partes velhas, lisa. Lacínulas ausentes, às vezes surgindo pequenos lóbulos jovens adventícios nas margens, $0,3-2,2 \times 0,2-0,8 \mathrm{~mm}$, simples a irregulares, planos, subtruncados ou subarredondados. Máculas ausentes. Cílios marginais escassos e esparsos, mais freqüentes nas axilas dos lobos, $0,10-0,80(-1,20) \times$ ca. $0,05 \mathrm{~mm}$, simples ou muito raramente irregulares. Sorais e pústulas ausentes. Isídios granulares a cilíndricos lisos, 0,05-0,70 (em alguns espécimes até $1,20-2,10$ de altura máxima) x $0,05-0,10(-0,20) \mathrm{mm}$, simples a coralóides, eretos ou parcialmente procumbentes, tortuosos, firmes, concoloridos ou parcialmente de ápices marrons, eciliados, mais comuns em ápices de dobras passando a laminais, às vezes surgindo também nas margens de lobos mais velhos. Medula branca, sem pigmentações. Lado de baixo negro, lustroso, liso a pouco rugoso ou pouco venado. Margem inferior marrom, lustrosa, 0,5-3,0 $(-6,0) \mathrm{mm}$ larg., nua, atenuada, lisa a pouco rugosa ou pouco venada. Rizinas negras, simples a furcadas ou raramente irregulares, $0,20-1,20$ (muito raro $-2,50) \times$ ca. $0,05(-0,10) \mathrm{mm}$, de freqüentes a abundantes, distribuídas homogeneamente. Apotécios submarginais a laminais, côncavos a cupuliformes, 0,3-7,5 $\mathrm{mm}$ diâm., subpedicelados, de margem lisa quando jovens, porém logo crenada pela formação de isídios e tornando-se densamente isidiada, de anfitécio e pedicelo lisos e que também tornam-se mais isidiados conforme envelhecem. Disco marrom, não pruinoso, imperfurado. Ascósporos elipsóides, $(20,0-) 22,5-32,0(-38,0) \times(11,5-) 13,0-16,5(-19,0) \mu \mathrm{m}$, epispório 2,5-3,0 $(-4,0) \mu \mathrm{m}$. Picnídios submarginais comuns, mais raramente laminais, de ostíolo negro. Conídios baciliformes, (4,0-) 5,0-7,0 x ca. $1,0 \mu \mathrm{m}$.

Substâncias de importância taxonômica: atranorina (córtex superior), ácido stíctico, constíctico, criptostíctico, outros ácidos do complexo stíctico e variavelmente norlobaridona (medula).

Material estudado: Brasil. São Paulo: Bertioga, Praia de Guaratuba, à Beira do Rio Guaratuba, manguezal próximo à mata de restinga, 1/VII/1981, M.P.Marcelli \& J.Vieira Filho 1659 (SP); idem, no cruzamento com a antiga rodovia, manguezal na margem sul do rio, 21/X/1982, M.P.Marcelli 1658, 1665, 1666 (SP). Cananéia, Ilha do Cardoso, restinga da Vila Marujá, vegetação de restinga pós-dunas ao S da ilha, 20/X/1981, M.P.Marcelli 1749, 1765, 1776, 1777 (SP); idem, Praia do Pereirinha, às margens do Rio Perequê, manguezal perto da base, 21/X/1981, M.P.Marcelli 1568 (SP). Iguape, Barra do Ribeira, entre o "Rio" Suamirim e o oceano, vegetação pós-dunas próximo da foz do rio, 21/VII/1989, M.P.Marcelli \& O.Yano 6946 (SP). Itanhaém, Rodovia Padre Manoel da Nóbrega (SP-55) Km 108, no cruzamento com o Rio Itanhaém, manguezal ao lado da rodovia, na margem direita do rio, 10/I/1979, M.P.Marcelli \& L.R.Fontes 1661, 1662, 1663, 1664, 1686 (SP); idem, 1/IV/1988, M.P.Marcelli \& L.R.Fontes 2385 (SP); idem, 16/VII/1988, M.P.Marcelli \& L.Y.Nagaoka 3674 (SP); idem, manguezal no contato com a mata de restinga, 17/VII/1988, M.P.Marcelli \& L.Y.Nagaoka 3683, 3686, 3689 (SP); idem, 15/X/2003, P.Jungbluth et al. 637 (SP); idem, 15/X/2003, S.B.Barbosa et al. s.n. (SP). Peruíbe, margem esquerda do Rio Guaraú, trilha na beira da 
314 Benatti \& Marcelli: Espécies de Parmotrema (Parmeliaceae, Ascomycota) do litoral centro-sul do estado de São Paulo III...

mata de restinga alta, 23/VII/1988, M.P.Marcelli \& O.Yano 3913 (SP); idem, nas proximidades da foz, Base da Faculdade de Ciência e Tecnologia Santa Cecília, 24-VII-1988, M.P.Marcelli 3972, 3976, 3977, 3978 A (SP); idem, Reserva Ecológica Juréia-Itatins, Núcleo Guarauzinho, no sopé da Serra do Mar, costão rochoso no lado norte da praia, 29-VII1993, M.P.Marcelli \& O.Yano 23774, 23799, 23800 (SP).

Distribuição: América do Norte e América do Sul. Brasil: MG, PR, RS, e SP (Esslinger 1997; Fleig 1997; Ribeiro 1998; Benatti 2005; Canêz 2005; Spielmann 2005).

Comentários: Esta é a espécie isidiada do gênero mais facilmente encontrada na área de estudo. É caracterizada pelo talo plano, escassez de cílios marginais, e pelos isídios eciliados simples a coralóides formados principalmente sobre os ápices de dobras.

Os isídios apresentam grande variação, sendo que nos menores talos observados são quase totalmente simples e granulares, muito pequenos, não ultrapassando $0,30 \mathrm{~mm}$ de altura, enquanto que em talos mais desenvolvidos são quase todos ramificados a coralóides, grandes, às vezes ultrapassando 2,0 $\mathrm{mm}$ alt. Na grande maioria dos espécimes, entretanto, os isídios têm ramificação simples a coralóide e medem até $0,70 \mathrm{~mm}$ de altura.

A grande variabilidade no padrão de ramificação dos isídios é mencionada por alguns autores (Fleig 1997; Donha 2005) enquanto outros mencionam uma variação menor (Ribeiro 1998; Eliasaro 2001; Canêz 2005). O tamanho da maioria dos isídios observados está mais de acordo com as medições citadas por Fleig (1997), mesmo nos talos em que estes alcançam tamanhos maiores. Notou-se que a altura maior de $0,7 \mathrm{~mm}$ ocorre apenas em parte dos isídios, enquanto que a maioria não ultrapassa esse limite. Os isídios dos espécimes menores analisados têm aparentemente o mesmo padrão de ramificação e altura que os do espécime encontrado por Canêz (2005), que também se trata de um talo pequeno.

Todos os espécimes analisados têm cílios marginais extremamente esparsos e restritos em sua maioria às axilas dos lobos (é a distribuição mais comum segundo os autores anteriormente citados). O tamanho dos ascósporos encontrados é similar ao mencionado por Fleig (1997) para os espécimes do Rio Grande do Sul, que medem 19,0-31,0 $\mu \mathrm{m}$. Foram encontrados ocasionalmente ascósporos com até $38,0 \mu \mathrm{m}$ em nosso material, ainda que apenas em alguns espécimes e em quantidade muito pequena.

A variação encontrada nos isídios levantou dúvida sobre a possibilidade de haverem mais de um táxon no material. Entretanto, a cromatografia em camada delgada dos espécimes demonstrou a mesma composição química com variações muito pequenas, apenas quanto às concentrações das substâncias.

Encontrada anteriormente por Fleig (1997) e mais recentemente por Canêz (2005), a substância norlobaridona é comentada por Eliasaro (2001) como sendo provavelmente acessória. A quantidade de norlobaridona encontrada nos espécimes deste trabalho é realmente variável, com reação do teste $\mathrm{KC}+$ róseo variando de notável a fraca ou inexistente conforme o talo, sendo que a substância não foi detectada em alguns espécimes cromatografados.

Segundo a literatura (Fleig 199; Ribeiro 1998; Brodo et al. 2001; Eliasaro 2001), Parmotrema crinitum (Acharius) Hale é provavelmente a espécie mais facilmente confundida com $P$. internexum. Contudo, $P$. crinitum diferencia-se segundo os autores pelo talo menos adnato, mais coriáceo, lobos mais largos (0,7-1,5 cm segundo Fleig 1997), margens mais amplamente ciliadas, e pelos isídios que são ao menos em parte evidentemente ciliados.

A descrição de Hale (1965) de Parmotrema peralbidum (Hale) Hale menciona lobos mais largos que os de $P$. internexum (com até $15,0 \mathrm{~mm}$ ), isídios simples e finos, e contém ácido protocetrárico medular. Segundo Canêz (2005), os lobos de $P$. peralbidum são também mais amontoados nas partes centrais do talo, e têm margens involutas.

Parmotrema flavotinctum (Hale) Hale (Hale 1965) difere de $P$. internexum por formar lacínulas que, por sua vez, formam isídios coralóides, cujos ápices se decompõem em sorédios, que o autor comparou também às estruturas isidióides arbusculares que são observadas em Parmotrema fasciculatum (Vainio) Hale (=Parmelia fasciculata Vainio). Além da morfologia diferente dos isídios, P. flavotinctum tem margens mais ciliadas e possui apenas atranorina como componente químico medular.

Parmelia allardii Hale, um sinônimo de Parmotrema mellissii (Dodge) Hale (Hale 1959; Hale 1965; Benatti 2005) também difere de $P$. internexum por formar agrupamentos isidióides arbusculares que se tornam decorticados apicalmente, mas que diferentemente de P. flavotinctum mantém o aspecto isidióide sem originar sorédios granulares como os que são mencionados para P. mellissii; os isídios de Parmelia allardii normalmente têm cílios longos, ainda maiores que os próprios isídios, e a química medular é composta pelos ácidos alectorônico e $\alpha$-colatólico.

\section{Parmotrema lobulatum Marcelli \& Hale, Mycotaxon} 25: 86. 1986.

Fig. 6a-b

Talo sublobado, verde acinzentado, de até $6,0 \mathrm{~cm}$ diâm., corticícola. Lobos de ramificação irregular, 1,0-3,0 $(-4,0)$ $\mathrm{mm}$ larg., imbricados, pouco adnatos e pouco adpressos nas partes distais, tornando-se mais amontoados, elevados e soltos conforme ficam lacinulados em direção ao centro, os ápices subarredondados ou irregulares, tornando-se freqüentemente subcanaliculados conforme se tornam lacinulados, as margens lisas, subcrenadas a irregulares, subplanas, subonduladas, incisas, lacinuladas e muito lobuladas. Superfície irregularmente quebrada, lisa. Lacínulas marginais comuns, quase sempre eciliadas, mais abundantes nas partes velhas centrais onde tornam-se muito amontoadas e em parte originadas a partir 

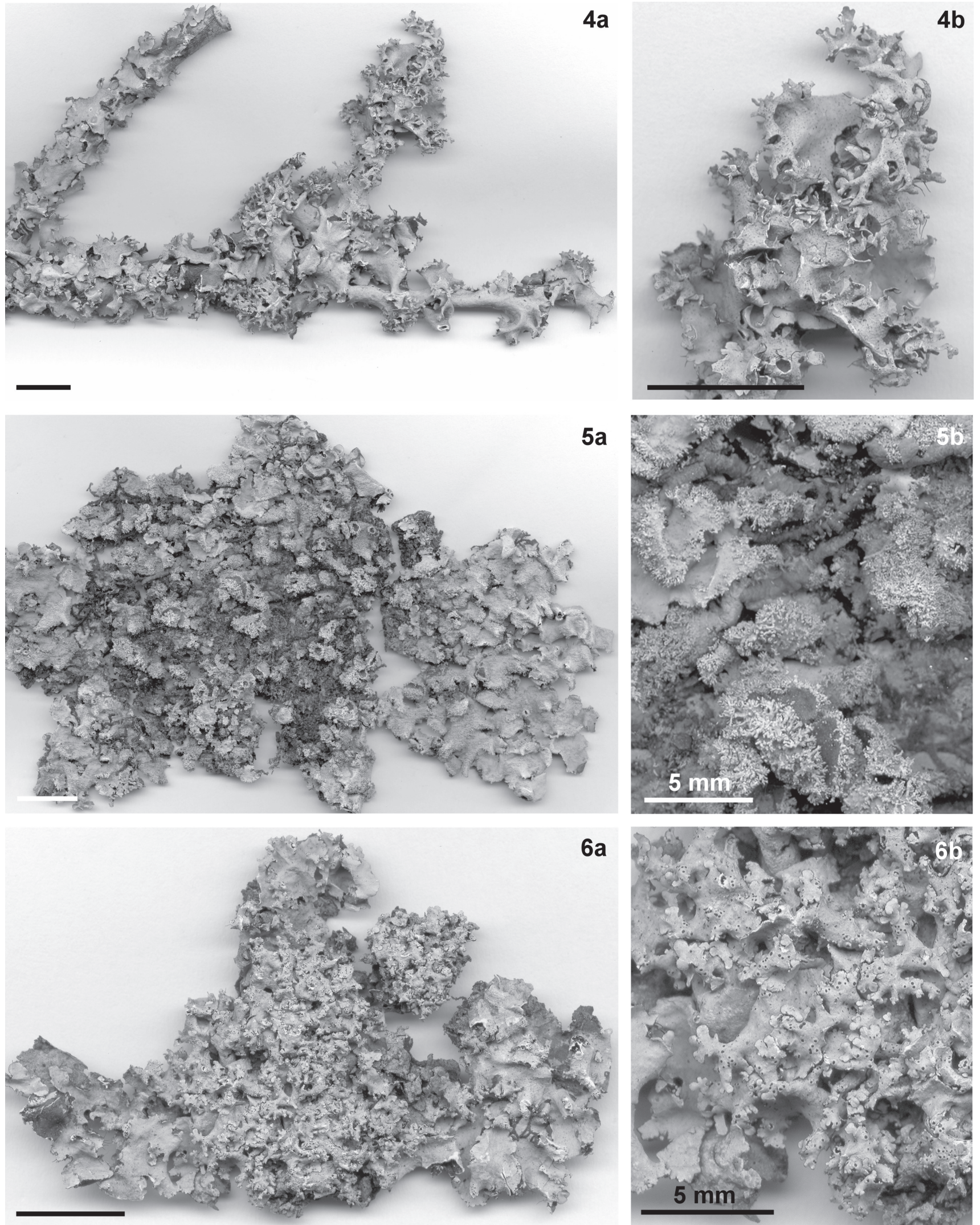

Figura 4. Parmotema eliasaroanum Benatti, Marcelli \& Elix. a. Hábito. b. Detalhe (Marcelli 1757). Figura 5. Parmotrema internexum (Nylander) Hale a. Hábito. b. Detalhe (Marcelli 14379). Figura 6. Parmotrema lobulatum Marcelli \& Hale. a. Hábito. b. Detalhe (Marcelli 38, isótipo). Escalas nas figuras $=1 \mathrm{~cm}$, exceto onde indicado. 
dos ápices canaliculados dos lobos, planas a subcanaliculadas, $0,4-1,8 \times 0,3-0,6 \mathrm{~mm}$, truncadas a subtruncadas, misturadas a pequenos lóbulos procumbentes que surgem tanto das margens dos lobos como das margens das lacínulas, medindo 0,2-0,4 x $0,1-0,2 \mathrm{~mm}$, simples a irregulares, ambos com lado de baixo marrom concolorido a margem inferior. Máculas ausentes. Cílios marginais negros, simples, $0,1-1,5 \mathrm{x}$ ca. $0,05 \mathrm{~mm}$, freqüentes, porém ausentes nas lacínulas. Sorais, pústulas e isídios ausentes. Medula branca, sem pigmentações. Lado de baixo negro, lustroso, liso a pouco rugoso, pouco papilado. Margem inferior marrom, lustrosa, 0,5-1,5 mm larg., nua, atenuada, lisa. Rizinas negras, simples, $0,1-0,6$ (muito raramente $-1,0)$ x ca. $0,05 \mathrm{~mm}$, escassas tornando-se mais freqüentes em alguns poucos trechos, homogeneamente distribuídas. Apotécios não encontrados. Picnídios submarginais comuns, abundantes nos lóbulos, de ostíolo negro. Conídios filiformes curtos, 7,0-9,0 x ca. 1,0 $\mu \mathrm{m}$.

Substâncias de importância taxonômica: atranorina (córtex superior), ácidos stíctico, constíctico, menegaziaco, criptostíctico, peristíctico, substíctico e hipostíctico (medula).

Material estudado: BRASIL. São Paulo: Bertioga, Praia de Guaratuba, à beira do Rio Guaratuba, no cruzamento com a antiga rodovia, manguezal na margem sul do rio, 13/I/1982, M.P.Marcelli 38 (isótipo, SP), 1598 (SP).

Distribuição conhecida: América do Sul. Brasil: SP (Hale 1986; Benatti 2005; Marcelli et al. 2008).

Comentários: Esta espécie é caracterizada pela ausência de propágulos vegetativos, formação de lacínulas marginais planas a subcanaliculadas, misturadas a uma grande quantidade de pequenos lóbulos, margem inferior marrom nua e muito estreita, e rizinas esparsas e curtas.

Hale (1986) mencionou uma largura maior para os lobos $(3,0-6,0 \mathrm{~mm})$ do que a vista aqui, sendo que tanto o isótipo quanto um topotipo estudados apresentam lobos bem estreitos, que dificilmente ultrapassam 3,0 mm larg. A formação de lacínulas também não foi mencionada pelo autor, mas podem ser percebidas formando-se em meio aos lóbulos por toda a margem, variando de planas nas margens a subcanaliculadas principalmente nas das partes centrais do talo, de onde surgem também a partir dos ápices subcanaliculados dos lobos, onde são mais amontoadas.

Hale (1986a) relacionou $P$. lobulatum a $P$. crinitum (Acharius) Choisy, devido à compatibilidade da química medular; contudo esta espécie tem os lobos bem mais largos $(6,0-12,0 \mathrm{~mm})$, isídios freqüentemente ciliados, é mais rizinada e não forma lóbulos ou lacínulas. Parmotrema internexum (Nylander) Hale ex DePriest \& B. Hale difere de $P$. lobulatum por também ser isidiada (mas com isídios eciliados), pelos lobos um pouco mais largos $[1,5-4,5(-8,0)$ $\mathrm{mm}]$, pelos cílios marginais esparsos, pela ausência de lóbulos ou de lacínulas, e pelo córtex inferior mais rizinado.
Os espécimes de P. eliasaroanum Benatti, Marcelli \& Elix foram supostos inicialmente tratarem-se de $P$. lobulatum, antes do isótipo ter sido encontrado e examinado. Parmotrema eliasaroanum é também muito lacinulada, possui química medular semelhante, mas não apresenta formação de lóbulos como $P$. lobulatum, tem composição química medular diferentes ácidos do complexo stíctico e outras substâncias, facilmente diferenciadas em CCD e CLAP. Além disto, $P$. eliasaroanum apresenta lobos de largura maior (3,0-6,0 mm), lacínulas mais longas e freqüentemente ciliadas, margem quase inteiramente de coloração creme mesmo em lobos não lacinulados (margens marrons só observadas em alguns poucos lobos jovens distais), rizinas mais freqüentes, mais longas $(-1,3 \mathrm{~mm})$ e agrupadas, e conídios que baciliformes a filiformes curtos constantemente 4,0-8,0 $\mu \mathrm{m}$ (ver mais comentários em P. eliasaroanum).

\section{Parmotrema milanezii Marcelli, Benatti \& Elix, Myco-} taxon 105: 244. 2008.

Fig. 7a-b

Talo lobado, cinza esverdeado claro, de até $20,5 \mathrm{~cm}$ diâm., submembranáceo a membranáceo, corticícola ou ramulícola. Lobos de ramificação irregular, 3,5-11,0 $(-20,0) \mathrm{mm}$ larg., contíguos a pouco imbricados, raramente pouco amontoados no centro do talo, adnatos às vezes pouco elevados quando sorediados, adpressos a pouco adpressos, os ápices arredondados a subarredondados, de planos a subplanos, as margens lisas a subcrenadas, planas próximas aos ápices ascendendo levemente em direção ao centro, em parte subonduladas, involutas ou revolutas conforme tornam-se sorediadas, inteiras a incisas, parcialmente sublacinuladas. Superfície contínua nas partes distais tornando-se irregularmente quebrada na maior parte do talo, de lisa a pouco rugosa. Lacínulas marginais curtas, mais comuns no centro, planas, 0,4-2,2 mm x 0,3-0,8 $\mathrm{mm}$, simples ou mais raramente furcadas, truncadas, lado de baixo branco ou às vezes negro ou variegado quando sorediadas, menos freqüentemente concolorido à margem inferior, às vezes misturadas a escassos lóbulos jovens adventícios. Máculas ausentes. Cílios marginais negros, em sua maioria furcados, dicotômicos ou irregularmente ramificados a parcialmente simples, $0,10-2,50(-3,80) \mathrm{x}$ ca. $0,05(-0,10) \mathrm{mm}$, abundantes ou um pouco menos freqüentes em algumas partes, geralmente ausentes nos ápices dos lobos. Sorais subcapitados a lineares interrompidos, em geral surgindo nos ápices das pequenas lacínulas marginais, com freqüência coalescendo lateralmente e adensando-se, tornando-se em parte irregulares e, às vezes, um pouco soerguidos. Sorédios farinhosos a subgranulares. Pústulas e isídios ausentes. Medula branca, sem pigmentações. Lado de baixo negro, lustroso, liso a rugoso ou venado, raramente pouco papilado, parcialmente desprovido de rizinas. Margem inferior marrom, tornando-se branca ou creme sob lobos sorediados, lustrosa, 1,5-6,5 $(-8,0) \mathrm{mm}$ 
larg., nua, atenuada quando marrom a nítida quando branca ou creme, lisa a pouco venada, raramente rugosa ou papilada. Rizinas negras, simples ou às vezes furcadas, $0,2-0,8$ $(-1,9) \times 0,05-0,10 \mathrm{~mm}$, escassas a freqüentes, agrupadas. Apotécio (somente um em um único espécime foi encontrado) côncavo, 2,3 mm diâm., submarginal, subpedicelado, margem lisa, sorediada, eciliada, anfitécio e pedicelo lisos. Disco marrom, não pruinoso, imperfurado. Ascósporos não encontrados (himênio sem ascos). Picnídios submarginais, muito escassos, de ostíolo negro. Conídios não encontrados.

Substâncias de importância taxonômica: atranorina (córtex superior), ácidos equinocárpico, protocetrárico, subvirênsico, convirênsico, conequinocárpico, subequinocárpico, secalônico A e uma substância desconhecida.

Material estudado: BRASIL. São Paulo: Itanhaém, Bairro Jardim Grandesp, km 116 da Rodovia Padre Manoel da Nóbrega, entre a rodovia e a Serra do Mar, mata de restinga alta ca. $2 \mathrm{~km}$ da rodovia, à beira de trilha que segue em direção à Serra na divisa de quadras, 30/I/1982, M.P.Marcelli \& J.Vieira Filho 9193 (holótipo, SP). Ilha Comprida, parte sul da ilha, à beira da estrada próximo à balsa para Cananéia, mata de restinga baixa, sobre galho de árvore no interior da mata, 2/IV/2004, L.S. Canêz et al. 1291, 1312 (SP).

Distribuição Conhecida: América do Sul. Brasil: SP (Benatti 2005; Marcelli et al. 2008).

Comentários: Parmotrema milanezii é caracterizada pelo talo plano e adnato, membranáceo, de margens lacinuladas e sorediadas, com cílios abundantes e de ramificação diversa surgindo mesmo entre os sorédios, e rizinas agrupadas e esparsas.

A característica que mais chama a atenção é a intensa formação de cílios marginais, que vão se estabelecendo em meio aos sorais mesmo com a desintegração das margens para a formação dos sorédios, algumas vezes até mesmo ficando restritos a grãos de sorédios, e assim facilmente destacáveis. É comum observar em talos de espécies sorediadas de Parmotrema que cílios tendem a não surgir nas partes das margens em que se formam os sorais, como facilmente visto nas espécies encontradas no litoral (Benatti 2005). Embora os cílios em $P$. milanezii tenham uma variação bastante ampla no padrão de ramificação, os ramificados são geralmente os mais abundantes. Apenas em um dos espécimes analisados a proporção dos cílios foi mais ou menos equilibrada dos simples para os ramificados.

Parmotrema dilatatum (Vainio) Hale assemelha-se à $P$. milanezii, porém diferem pela completa ausência ou escassez de cílios nas margens. Quase todos os espécimes de $P$. dilatatum analisados são eciliados; espécimes ciliados (Hale 1965; Fleig 1997; Ribeiro 1998; Donha 2005) têm cílios muito esparsos, simples e muito curtos e geralmente restritos às axilas dos lobos ou a áreas regeneradas.
Outra diferença é que os talos de $P$. milanezii são todos membranáceos e de lobos aplanados, elevados apenas quando sorediados. Talos de $P$. dilatatum apresentam grande variação, mas a maioria dos encontrados na localidade de estudo bem como a dos que são mencionados na literatura varia de subcoriáceo a coriáceo (ver comentários sobre $P$. dilatatum e a Tabela 1). Parmotrema milanezii tem talos também mais acinzentados e claros do que qualquer um dos espécimes de $P$. dilatatum aqui analisados, mesmo comparando os herborizados, que ficam mais pardacentos e escuros com o tempo.

Apesar de algo semelhante, o formato e a disposição dos sorais nas margens e nas lacínulas de Parmotrema perlatum é bastante peculiar desta espécie e um tanto quanto diferente do de P. milanezii com sorais de formato mais capitado ou labriforme, confluindo lateralmente de forma mais sutil, e com menos freqüência e intensidade como ocorre com os sorais lineares interrompidos ou irregulares comuns em P. milanezii ou P. dilatatum. Os sorais de $P$. perlatum lembram em alguns trechos o aspecto de um "colar de pérolas", e embora as margens sejam também ciliadas como em P. milanezii, os cílios são quase sempre simples (raros furcados) e mais curtos (raramente ultrapassando 1,5 $\mathrm{mm}$ de comprimento), e que não surgem nas áreas sorediadas. Além das diferenças dos sorais e dos cílios, talos de P. perlatum têm ainda lobos mais estreitos (1,5-6,0 $\mathrm{mm}$ larg.), córtex inferior mais abundante e homogeneamente rizinado que o de $P$. milanezii, e a medula apresenta ácidos do complexo stíctico e ácido menegaziáico, sem apresentar ácidos equinocárpico e protocetrárico.

A descrição de Parmotrema schindleri Hale é próxima à de $P$. milanezii, devido ao aspecto geral do talo, formato e disposição dos sorais nas margens e sobre lacínulas, e pela composição química medular. Entretanto, segundo a descrição original (Hale 1986), esta espécie difere de $P$. milanezii pelos cílios mais curtos e esparsos $(0,5-1,0 \mathrm{~mm})$, restritos as axilas dos lobos, e pela presença de ácido girofórico medular além do ácido protocetrárico, sem o ácido equinocárpico. Ainda segundo o autor, $P$. schindlerii aparenta ser estritamente saxícola.

7. Parmotrema perlatum (Hudson) M. Choisy, Bulletin Mensuel de la Societe Linneenne de Lyon 21: 174. 1952. Lichen perlatus Hudson, Flora Anglica 1: 2.1762.

Talo lobado a sublobado, verde acinzentado, de até $16,0 \mathrm{~cm}$ diâm., membranáceo, corticícola ou ramulícola. Lobos de ramificação irregular, 1,5-6,0 mm larg., de imbricados a bastante amontoados, adnatos a pouco adnatos, às vezes um pouco mais elevados no centro do talo quando lacinulados e sorediados, adpressos a pouco adpressos, os ápices subarredondados, de subplanos a subcôncavos, as margens lisas nas partes adjacentes aos ápices, tornando-se subcrenadas na maior parte do talo, de subplanas a subas- 
318 Benatti \& Marcelli: Espécies de Parmotrema (Parmeliaceae, Ascomycota) do litoral centro-sul do estado de São Paulo III...

cendentes, de subonduladas a um pouco mais onduladas e involutas quando sorediadas, incisas, sublacinuladas. Superfície contínua ou raramente com quebras irregulares, lisa. Lacínulas marginais regulares muito curtas, mais freqüentes em direção ao centro, planas, $0,2-0,8 \mathrm{~mm}$ x $0,2-0,6 \mathrm{~mm}$, simples a mais raramente furcadas ou irregulares, truncadas, lado de baixo creme quando sorediadas ou concolorido à margem inferior. Máculas ausentes. Cílios marginais negros, simples, raramente furcados, $0,10-1,60 \mathrm{x}$ ca. $0,05 \mathrm{~mm}$, de freqüentes a abundantes. Sorais capitados a labriformes, surgindo nos ápices de pequenas lacínulas marginais ou em menor parte diretamente a partir das margens, às vezes coalescendo lateralmente tornando-se subcontínuos, parcialmente adensando e tornando-se aparentemente lineares interrompidos, às vezes também surgindo submarginais e estendendo-se pela lâmina, tornandose irregulares. Sorédios subgranulares ou mais raramente granulares. Pústulas e isídios ausentes. Medula branca, sem pigmentações. Lado de baixo negro, lustroso, liso a pouco venado, pouco papilado. Margem inferior marrom clara, tornando-se creme quando em lobos lacinulados e sorediados, lustrosa, (0,5-) 1,0-3,5 mm larg., nua, atenuada quando marrom a nítida quando creme, lisa a pouco rugosa. Rizinas negras, simples, ocasionalmente furcadas ou irregulares, $0,2-0,8(-1,7$ próximo às margens) $\mathrm{x}$ ca. 0,05 $\mathrm{mm}$, abundantes, às vezes um pouco menos freqüentes em alguns trechos, homogeneamente distribuídas. Apotécios não encontrados. Picnídios submarginais, muito escassos, de ostíolo negro. Conídios não encontrados.

Substâncias de importância taxonômica: atranorina (córtex superior), ácidos stíctico, constíctico, criptostíctico, conorstíctico (?) e menegaziaco (medula).

Material estudado: BRASIL. São Paulo: Itanhaém, Rodovia Padre Manoel da Nóbrega (SP-55) Km 108, no cruzamento com o Rio Itanhaém, manguezal ao lado da rodovia, na margem direita do rio, 1/IV/1988, M.P.Marcelli \& L.R.Fontes 2393, 2423 (SP). Praia Grande, Bairro Cidade Ocean, ca. $1 \mathrm{~km}$ após a estátua de Iemanjá, $2 \mathrm{~km}$ da de Netuno, em direção a Mongaguá, terreno entre a praia e a estrada com resíduo de vegetação de duna posterior e mata de restinga, 6/VII/1988, M.P.Marcelli \& J.Vieira Filho 3076, 3080 (SP).

Distribuição conhecida: Oceania, Ásia, Pacífico Norte, África, Europa, Atlântico Norte, América do Norte, América Central, Caribe e América do Sul. Brasil: MG, PR, RS, SC e SP (Grassi 1950; Hale 1965; Osório 1972; Krog \& Swinscow 1981; Swinscow \& Krog 1988; Fleig 1997; Ribeiro 1998; Eliasaro 2001; Kurokawa \& Lai 2001; Feuerer 2005; Benatti 2005; Canêz 2005; Spielmann 2005). Obs.: várias destas bibliografias se referem a espécie quando passou a ser chamada Parmotrema chinense (Osbeck) Hale $\&$ Ahti (=Lichen chinensis Osbeck), que por anos pensou-se ser verdadeiramente o nome mais antigo da espécie (Hale \& Ahti 1986).

Comentários: Parmotrema perlatum tem como principais características o aspecto típico dos sorais capitados marginais dispostos lateralmente nos ápices de pequenas lacínulas, os talos membranáceos de superfície contínua, os cílios marginais simples e freqüentes, e as rizinas abundantes homogeneamente espalhadas pelo córtex inferior.

Antes do nome de Lichen chinensis Osbeck ter sido descoberto por Hale \& Ahti e combinado em Parmotrema (1986), Parmelia perlata (Hudson) Acharius e posteriormente Parmotrema perlatum (Hudson) M. Choisy foram os nomes pelo qual o grupo de espécies de margens sorediadas e ciliadas contendo ácido stíctico ficaram mais amplamente conhecidos. Recentemente (Hawksworth 2004), foi reencontrado o tipo de $P$. chinense, que provou se tratar de outra espécie [P. tinctorum (Nylander) Hale], e que foi considerada como não validamente publicada, ficando assim restabelecido o nome P. perlatum.

A principal característica da espécie está relacionada aos sorais. Estes são em sua maioria orbiculares ou, quando mais desenvolvidos, labriformes (devido ao aumento da largura dos lobos e das lacínulas), surgindo constantemente nos ápices de pequenas lacínulas marginais por todo o talo. Às vezes os sorais coalescem lateralmente e, devido à sua disposição nas margens, dá ao conjunto destas estruturas um formato e disposição peculiares semelhantes ao de um "colar de pérolas".

Conforme vão se adensando, os sorais recobrem as lacínulas, fazendo com que os lobos fiquem progressivamente mais sinuosos e involuam, dando às vezes uma falsa impressão de que são lineares interrompidos. Os sorais nesta espécie mais raramente tornam-se irregulares quando crescem a partir das margens e, ao coalescer, vão tornandose submarginais conforme avançam em direção à lâmina.

Embora este formato e modo de disposição sejam os mais citados em literatura (Hale 1965; Krog \& Swinscow 1981; Swinscow \& Krog 1988; Fleig 1997; Ribeiro 1998; Eliasaro 2001; Kurokawa \& lai 2001; Benatti 2005), apenas Hale (1965) descreveu os sorais de Parmelia perlata Hudson [=Parmotrema perlatum (Hudson) M. Choisy] como lineares.

Nenhum dos espécimes encontrados no litoral apresenta sorais efetivamente lineares [como os que são vistos em P. sancti-angeli (Lynge) Hale, por exemplo], e com base nos dados da literatura, seria possível supor que alguma espécie sinonimizada em Parmotrema perlatum talvez se trate de um táxon distinto, porém próximo na morfologia e na química medular.

Parmotrema dilatatum (Vainio) Hale tem lacínulas e sorais com forma e disposição semelhantes à de $P$. perlatum, assim como ocorre também com parte dos espécimes de $P$. clavuliferum (Räsänen) Streimann (Benatti \& Marcelli 2008). Entretanto, em ambas as espécies os sorais coalescentes marginais não adquirem um aspecto 

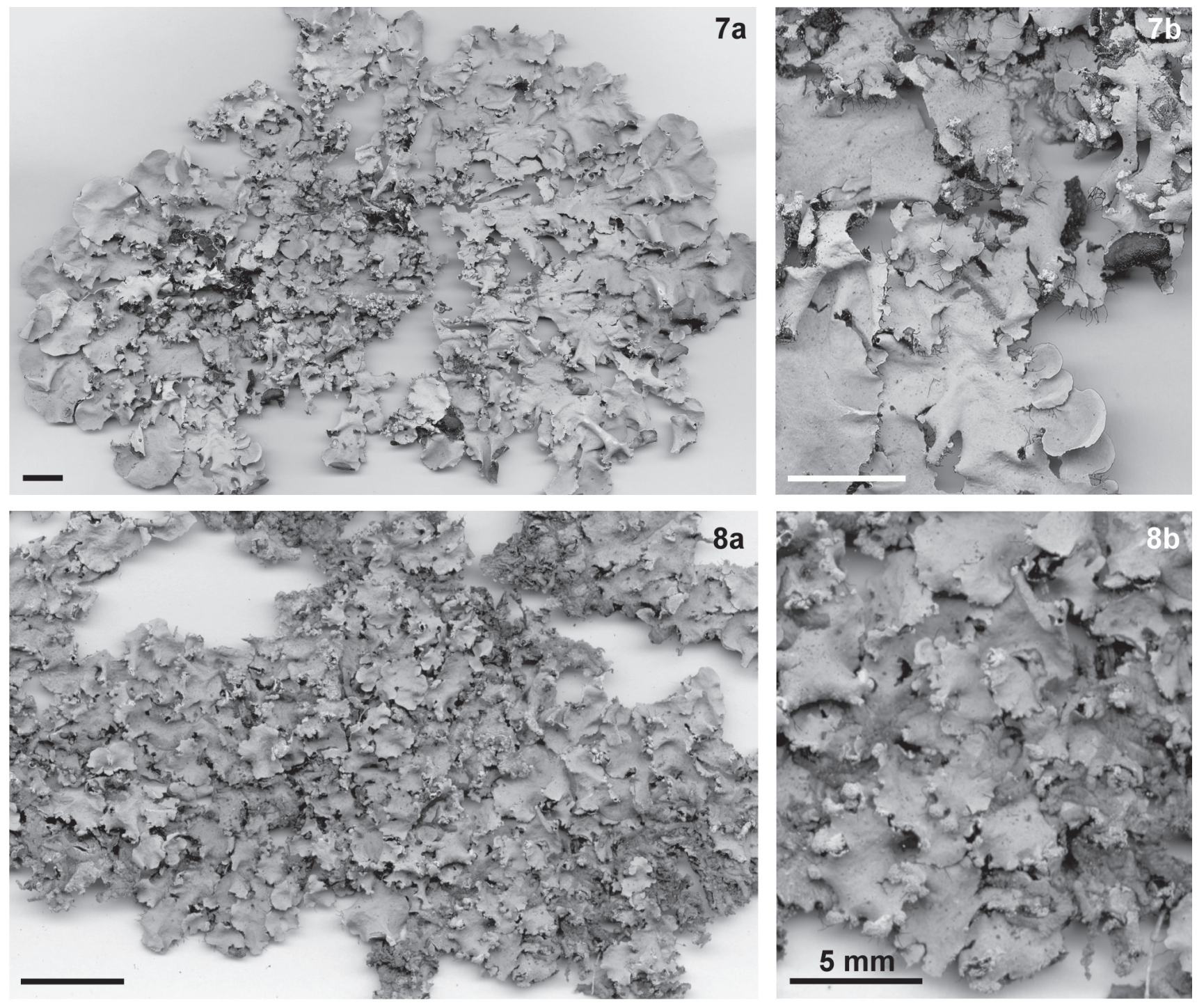

Figura 7. Parmotrema milanezii Marcelli, Benatti \& Elix. a. Hábito. b. Detalhe (Marcelli 9193, holótipo). Figura 8. Parmotrema perlatum (Hudson) M. Choisy. a. Hábito. b. Detalhe (Marcelli 6668). Escalas nas figuras $=1 \mathrm{~cm}$, exceto onde indicado.

tal qual o de um "colar de pérolas", como o típico encontrado em P.perlatum.

Outra diferença para com $P$. dilatatum é que esta espécie é normalmente eciliada, ou às vezes muito esparsamente ciliada, e pela química medular que apresenta ácidos equinocárpico e protocetrárico, ao invés de ácido stíctico e menegaziaico. Já parte dos espécimes de $P$. clavuliferum que apresenta sorais de aparência em comum com $P$. chinense, difere pelo surgimento e padrão rimoso-reticulado das máculas e rachaduras do córtex superior, pela ausência de uma margem inferior nua, e pela química medular que apresenta ácidos salazínico e consalazínico ao invés de stíctico e menegaziaico.

Parmotrema subochraceum Hale (Hale 1990; Benatti 2005) tem disposição mais ou menos similar de sorais, mas com as mesmas diferenças dos de $P$. perlatum que foram citadas para $P$. dilatatum e $P$. clavuliferum, diferin- do também por ter apenas ácido protocetrárico medular, e pelas hifas alaranjadas com pigmento $\mathrm{K}+$ vermelhoescuro entrelaçadas com as hifas brancas da medula, que são visíveis no lado de baixo do talo ao se raspar o córtex inferior.

Segundo Fleig (1997), P. rampoddense (Nylander) Hale e P. hypomiltoides (Vainio) Kurokawa diferem pela química medular, que apresenta ácidos alectorônico e $\alpha$ colatólico. Segundo a autora, quanto às características, a primeira é pouco ciliada, tem sorais lineares marginais que avançam pela lâmina, com pigmento do tipo esquirina $(\mathrm{K}+$ púrpura) raramente aparecendo em alguns pontos da medula, enquanto que a segunda tem sorédios subgranulares a granulares que formam estruturas marginais ascendentes irregulares a isidióides, córtex superior finamente maculado, e apresenta pigmento $\mathrm{K}+$ vermelho escuro nas partes distais do talo. 


\section{Referências bibliográficas}

Andrade, M.A.B. 1967. Contribuição ao conhecimento da ecologia das plantas das dunas do litoral do Estado de São Paulo. Boletim da Faculdade de Filosofia, Ciências e Letras da Universidade de São Paulo - Botânica 22: 3-170.

Andrade, M.A.B. \& Lamberti, A. 1965. A Vegetação. In A. Azevedo (coord.) A Baixada Santista - Aspectos Geográficos (Vol. 1): 151-177. São Paulo, EUDUSP.

Awasthi, D.D. 1976. Lichen genus Parmelia in India I - Subgenera Parmelia and Amphigymnia. Biological Memoirs 1(1-2): 155-229.

Asahina, Y. \& Shibata, S. 1954. Chemistry of Lichen Substances. Japan Society for the Promotion of Science. Ueno, Tóquio.

Benatti, M.N. 2005. Os gêneros Canomaculina, Parmotrema e Rimelia (Parmeliaceae, Ascomycetes) no litoral centro-sul do estado de São Paulo. Dissertação de Mestrado. Instituto de Botânica, São Paulo.

Benatti, M.N. \& Marcelli, M.P. 2007. Gêneros de fungos liquenizados dos manguezais do Sul-Sudeste do Brasil, com enfoque no manguezal do Rio Itanhaém, Estado de São Paulo. Acta Botanica Brasilica 21(4): 863-878.

Benatti, M.N. \& Marcelli, M.P. 2009. Espécies de Parmotrema (Parmeliaceae, Ascomycota) do litoral centro-sul do Estado de São Paulo I. Grupos químicos girofórico e lecanórico. Acta Botanica Brasilica 23(4): 1013-1026.

Brako, L.; Dibben, M.J. \& Amaral, I. 1985. Preliminary Notes on the macrolichens of Serra do Cachimbo, Northcentral Brazil. Acta Amazonica, suplemento 15(1-2): 123-135.

Brodo, I.M.; Sharnoff, S.D. \& Sharnoff, S. 2001. Lichens of North America. London, Yale University Press.

Bungartz, F. 2001. Analysis of lichen substances. Em http://ces.asu.edu/ ASULichens/plb 400/laboratory/ chemistry/tlc.html. Acessado em outubro de 2004.

Canêz, L.S. 2005. A Família Parmeliaceae na localidade de Fazenda da Estrela, Município de Vacaria, Rio Grande do Sul, Brasil. Dissertação de Mestrado. Instituto de Botânica, São Paulo.

Dodge, C.W. 1959. Some lichens of tropical Africa III. Parmeliaceae. Annals of the Missouri Botanical Garden 46: 39-193.

Donha, C.G. 2005. Os gêneros Canomaculina, Parmotrema e Rimelia (Ascomycota Liquenizados) na Área de Proteção Ambiental de Guaraqueçaba, Paraná, Brasil. Dissertação de Mestrado. Universidade Federal do Paraná.

Eiten, G. 1970. A Vegetação do Estado de São Paulo. Boletim do Instituto de Botânica 7: 1-22.

Eliasaro, S. 2001. Estudio taxonomico y floristico sobre las parmeliaceae sensu stricto (Ascomycota liquenizados) del Segundo Planalto del Estado de Paraná, Brasil. Tese de Doutorado. Facultad de Ciencias Exactas y Naturales, Universidad de Buenos Aires. Buenos Aires.

Eliasaro, S. \& Donha, C.G. 2003. The genera Canomaculina and Parmotrema (Parmeliaceae, lichenized Ascomycota) in Curitiba, Paraná State, Brazil. Revista Brasileira de Botânica 26(2): 239-247.

Elix, J.A. 1993. New Species in the Lichen Family Parmeliaceae (Ascomycotina) from Australia. Mycotaxon 47: 101-129.

Elix, J.A. 1994. Parmotrema. In Flora of Australia, Lichens. Introduction, Lecanorales 2. vol. 55: 140-162. Canberra, Australia Government Publishing Service.

Elix, J.A. 2001. Additional lichen records from Oceania 7. Parmeliaceae from Fiji. Australasian Lichenology 48: 34-37.

Esslinger, T.L. 1997. A cumulative checklist for the lichen-forming, lichenicolous and allied fungi of the continental United States and Canada. North Dakota State University: http://www.ndsu.nodak.edu/ instruct/esslinge/chcklst/chcklst7.htm (First Posted 1 December 1997, Most Recent Update 2 March 2004), Fargo, North Dakota.

Feuerer, T.E. (ed.) 2008. Checklists of lichens and lichenicolous fungi. Versão I Junho de 2006. In http://www.checklists.de.

Fink, B. 1905. How to collect and study lichens. The Bryologist 8(2): 22-27.

Fleig, M. 1997. Os gêneros Parmotrema, Rimelia e Rimeliella (LichenesAscomycota, Parmeliaceae) no Rio Grande do Sul, Brasil. Tese de Doutorado, Instituto de Biociências da Universidade de São Paulo. 250p.

Fleig, M., \& Riquelme, I. 1991. Liquens de Piraputanga, Mato Grosso do Sul, Brasil. Acta Botanica Brasilica 5(1): 3-12.
Fleig, M.; Grüninger, W.; Mayer, W-E. \& Hampp, R. 2008. Liquens da floresta com Araucária no Rio Grande do Sul. University of Tübingen, Germany.

Galloway, D.J. 1985. Flora of New Zealand - lichens. Wellington, Government Printer.

Galloway, D.J, \& Quilhot, W. 1998 Checklist of Chilean lichen-forming and lichenicolous fungi. Gayana Botanica 55(2): 111-185.

Grassi, M.M. 1950. Contribución al catálogo de liquenes argentinos. I. Lilloa 24: 5-294.

Hale, M.E. 1959b. New or interesting species of Parmelia from North and Tropical America. The Bryologist 62: 123-132.

Hale, M.E. 1965. A Monograph of the Parmelia subgenus Amphigymnia. Contributions from the United States National Herbarium 36(5): 193-358.

Hale, ME. 1974. New combinations in the lichen genus Parmotrema Massalongo. Phytologia 28: 334-339.

Hale, M.E. 1979. How to know the Lichens. The Pictured-Key Nature Series. Dubuque, Iowa: WM. C. Brown Company Publishers. Dubuque. $246 \mathrm{p}$.

Hale, M.E. 1986. New species in the lichen Family Parmeliaceae (Ascomycotina). Mycotaxon 25: 85-93.

Hale, M.E. 1990. New species of Parmotrema (Ascomycotina: Parmeliaceae) from Tropical America. Bibliotheca Lichenologica 38: 109-119.

Hawksworth, D. L. 2004. Rediscovery of the original material of Osbeck's Lichen chinensis and the re-establishment of the name Parmotrema perlatum. Herzogia 17: 37-44.

Huneck, S. \& Yoshimura, I. 1996. Identification of Lichen Substances. Berlin, Springer-Verlag.

Krog, H. \& Swinscow, T.D.V. 1981. Parmelia subgenus Amphigymnia (lichens) in East Africa. Bulletin of British Museum of Natural History (Bot.) 9(3): 143-231.

Kurokawa, S. \& Lai, M. 2001. Parmelioid lichen genera and species in Taiwan. Mycotaxon 77: 225-284.

Louwhoff, S.H.J.J. \& Elix, J.A. 1998. The lichen family Parmeliaceae (Ascomycotina) on Lord Howe Island, Australia. Mycotaxon 68: 429-463.

Louwhoff, S.H.J.J. \& Elix, J.A. 1999. Parmotrema and allied lichen genera in Papua New Guinea. Bibliotheca Lichenologica 73: 1-152.

Magnusson, A H \& ;Zahlbruckner, A. 1944. Hawaiian lichens. II. The families Lecideaceae to Parmeliaceae. Arkiv för Botanik 31A, Nr. 6: 1-109.

Marcelli, M.P. 1990 (1991). Aspects of the foliose lichen flora of the southern-central coast of São Paulo State, Brazil. In D.J. Galloway (Ed). Tropical Lichens: Their Systematics, Conservation, and Ecology, Systematics Association Special Volume 43, p. 151-170. Oxford,Clarendon Press.

Marcelli, M.P. 1992. Ecologia Liquênica nos Manguezais do Sul-Sudeste Brasileiro. Bibliotheca Lichenologica 47: 1-310.

Marcelli MP. 2004. Checklist of lichens and lichenicolous fungi of Brazil. Version 1: June 2004. http://www.biologie.uni-hamburg.de/ checklists/brazil_1.htm.

Marcelli, M.P. \& Ribeiro, C.H. 2002. Twenty-one new species of Parmeliaceae from southern Brazil. Mitteilungen aus dem Institut für Allgemeine Botanik in Hamburg 30-32: 125-155.

Marcelli, M.P.; Benatti, M.N. \& Elix, J.A.. 2008. New species of Parmotrema containing protocetraric or stíctico acids from the coast of São Paulo State, southeastern Brazil. Mycotaxon 105:235-248.

Moore, B.J. 1968. The Macrolichen Flora of Florida. The Bryologist 71(3): 161-267.

Nash III, T.H. \& Elix, J.A. 2002. Parmotrema. Pp. 318-329. In: Nash III, T.H., Ryan, B.D., Gries, C. \& Bungartz, F. (eds.). Lichen Flora of the greater Sonoran Desert Region. Volume 1. Lichens Unlimited, Arizona State University, Tempe, Arizona, USA.

Orange, A.; James, P.W. \& White, F.J. 2001. Microchemical methods for the identification of lichens. London, The British Lichen Society.

Osorio, H.S. 1972. Contribution to the lichen flora of Uruguay VII. A preliminary catalogue. Comunicaciones Botánicas del Museo de Historia Natural de Montevideo 4(56): 1-46.

Osorio, H.S. 1992. Contributions to the lichen flora of Uruguay XXV. Lichens from Sierra San Miguel, Rocha Department. Boletín de la Sociedad Argentina de Botánica 28(1-4): 37-40. 
Osorio, H.S., Aguiar, L.W. \& Zanette, V.C. 1980. Contributions to the lichen flora of Brazil VII. Lichens from Montenegro and Triunfo, Rio Grande do Sul State. Comunicaciones Botánicas del Museo de Historia Natural de Montevideo 4(62): 1-8.

Ribeiro, C.H. 1998. A família Parmeliaceae (Ascomycota liquenizados) em Regiões montanhosas dos estados de Minas Gerais, Rio de Janeiro e São Paulo. Dissertação de Mestrado, Instituto de Biociências da Universidade de São Paulo, São Paulo.

Sérusiaux, E. 1984. Contribution to the study of lichens from Kivu (Zaire), Rwanda and Burundi. VIII. New and interesting species of parmeliaceous lichens. The Bryologist 87: 1-11.

Sipman, H. J. M. 2000. Checklist of the lichenized fungi of the Guianas http:/www.mnh.si.edu/ biodiversity/bdg/guilich3.html. Acessado em julho de 2005

Spielmann, A.A. 2005. A família Parmeliaceae (fungos liquenizados) nos barrancos e peraus da encosta da Serra Geral, no Vale do Rio
Pardo, Rio Grande do Sul, Brasil. Dissertação de Mestrado. Instituto de Botânica, São Paulo.

Swinscow, T.D.V. \& Krog, H. 1988. Macrolichens of East Africa. London, British Museum of Natural History.

Vainio, E.A. 1890. Étude sur la classification naturelle et la morphologie des Lichens du Brésil, pars prima. Acta Societatis pro Fauna et Flora Fennica 7(1): i-xxix, 1-247.

Vainio, E.A. 1909. Lichenes Insularum Philippinarum, I. Philippine Journal of Science. C, Bot., IV, 5: 651-662.

Walker, J.W. \& James, P.W. 1980. A revised guide to microchemical techniques for the identification of lichen products. Bulletin of the British Lichen Society 46(supl.) London: 13-29.

White, F.J. \& James, P.W. 1985. A new guide to microchemical techniques for the identification of lichen substances. Bulletin of the British Lichen Society 57(supl.) London: 1-41. 